\title{
The Upstream Spreading of Bottom-Trapped Plumes
}

\author{
RICARDO P. MATANO \\ College of Oceanic and Atmospheric Sciences, Oregon State University, Corvallis, Oregon \\ ELBIO D. PALMA \\ Departamento de Fisica, Universidad Nacional del Sur, and Instituto Argentino \\ de Oceanografía (CONICET), Bahia Blanca, Argentina
}

(Manuscript received 1 September 2009, in final form 8 March 2010)

\begin{abstract}
It is well known that numerical simulations of freshwater discharges produce plumes that spread in the direction opposite to that of the propagation of coastally trapped waves (the upstream direction). The lack of a theory explaining these motions in unforced environments deemed the numerical results suspect. Thus, it became a common practice in numerical studies to add a downstream mean flow to arrest the development of the upstream perturbation. This approach is generally unjustified, and it remains a matter of interest to determine if the upstream displacement produced by models is a geophysical phenomenon or a consequence of erroneous assumptions in the model setup. In this article, the results of highly idealized numerical experiments are used to investigate these matters. It is shown that this phenomenon is associated with the geostrophic adjustment of the discharge and that upstream motion is endemic to the baroclinic structure of bottom-trapped plumes. It is also shown that downstream displacements are generated by the cross-shelf barotropic pressure gradient generated by the propagation of coastally trapped waves. Sensitivity experiments indicate that the speed of upstream propagation and the density structure of the plume are affected by bottom friction, the slope of the bottom, and the magnitude of the density anomaly. Bottom friction in particular slows down the progression of the plume and changes its density structure, producing a more homogeneous downstream region and a more stratified upstream region.
\end{abstract}

\section{Introduction}

Buoyant discharges into the coastal ocean form lowdensity plumes that move primarily in the direction of coastally trapped waves (conventionally regarded as the "downstream" direction). Early numerical simulations of these discharges produced slower but significant upstream spreading (Chao and Boicourt 1986; Chapman and Lentz 1994; Kourafalou et al. 1996; Fong 1998; Garvine 1999; Yankovsky 2000; Garvine 2001). Although Beardsley et al. (1985) reported a similar phenomenon in the Yangtze River (East China Sea), the lack of other observational evidence, particularly along the wellsampled coasts of North America and Europe, made the previously referenced numerical results suspect (Garvine

Corresponding author address: Ricardo P. Matano, College of Oceanic and Atmospheric Sciences, Oregon State University, 104 COAS Administration Building, Corvallis, OR 97331-5503.

E-mail: rmatano@coas.oregonstate.edu
2001). It subsequently became a common practice in numerical studies to add a downstream mean flow solely to arrest the upstream development (Yankovsky and Chapman 1997; Fong and Geyer 2002; Narayanan and Garvine 2002; Guo and Valle-Levinson 2007). This practice is supported by observations in some specific regions, but more generally this approach is unjustified. Moreover, some observational studies suggest that plumes with an upstream component are present in some locales (e.g., the Ganges River in India, the Mackenzie River in Alaska, and the La Plata River in Argentina; Murty et al. 1992; Weingartner et al. 1999; Framiñan 2005; Piola et al. 2008; Fig. 1). In most cases, however, it is difficult to distinguish whether the reported phenomenon is produced by internal ocean dynamics or driven by external agents (e.g., tides, wind forcing, etc.; Yankovsky 2000). It thus remains a matter of interest to determine whether the upstream spreading of buoyant plumes produced by models is a natural geophysical phenomenon or a consequence of erroneous model assumptions. 


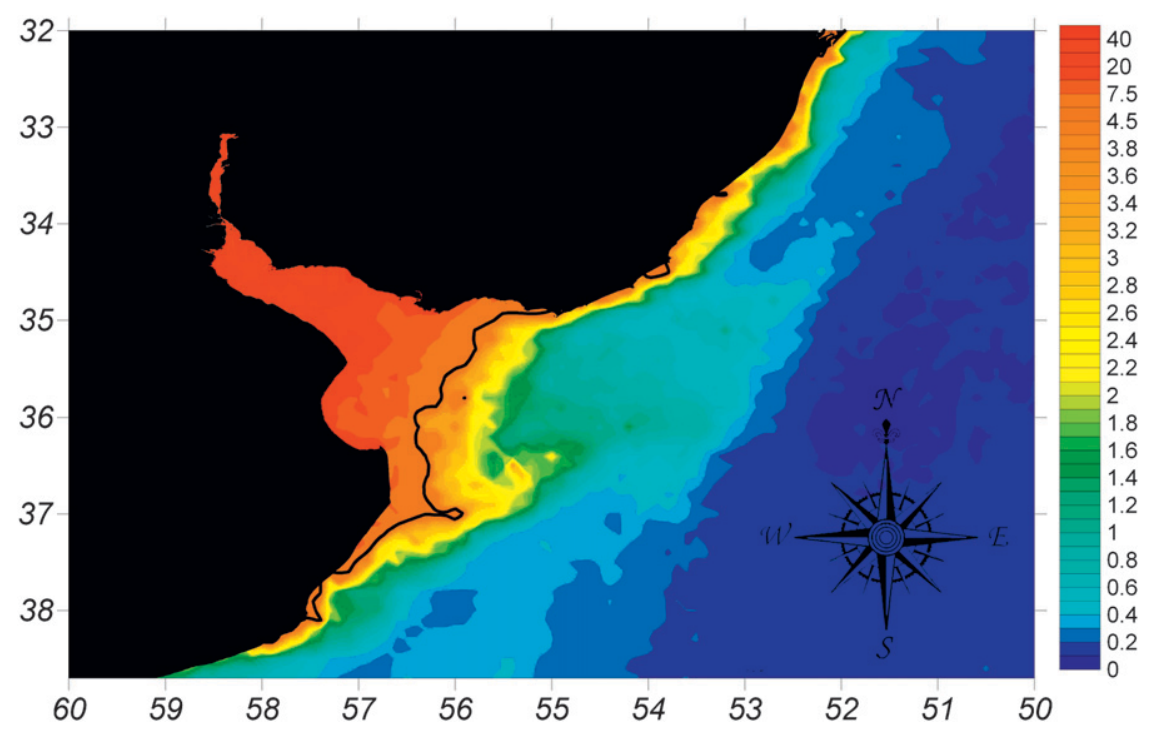

FIG. 1. Snapshot of surface chlorophyll in the La Plata River derived from surface chlorophyll $a$. Piola et al. (2008) showed that chlorophyll in this region is a good proxy of surface salinity with high chlorophyll corresponding to low salinity and vice versa. The thick black line, derived from in situ observations, marks the 31.0 isohaline separating river from ocean waters. Figure provided by A. R. Piola (Hydrographic Service of Argentina, 2009, personal communication).

Several studies have addressed the causes of the upstream spreading. Chapman and Lentz (1994) observed that the initial geostrophic adjustment of a bottomtrapped plume produces upstream velocities along the bottom that moves the density front farther upstream, but they did not explore the dynamical mechanisms that lead to this development. McCreary et al. (1997) argued that a freshwater input into the ocean drains the ambient water at the source region and forces an upstream propagation. Woods and Beardsley (1988) deduced that, during high river discharge events, cyclonic vorticity is induced by the topographic effect, but they noted that this vorticity generation does not lead to continuous upstream spreading, as in the case of baroclinic discharges. Kubokawa (1991) argued that upstream spreading is a consequence of the relatively low capacity of a downstream current to transport fluid with low potential vorticity. Kourafalou et al. (1996) posited that upstream spreading is caused by a nongeostrophic acceleration of the flow near the coast. Yankovsky (2000) postulated that upstream spreading of both surface- and bottom-trapped plumes is driven by the boundary conditions, specifically that fixed boundary conditions at the discharge site generate a divergence in the upper levels that leads to upstream propagation. Garvine (2001) further expanded these arguments and observed that changes in the depth of the inshore wall, the angle of discharge, and the addition of a channel connecting the inlet to the shelf significantly reduced upstream intrusions.
The insightful studies of Yankovsky and Garvine show that model configuration can influence upstream spreading, but these studies do not address its dynamical origins. They also show that, although changes to the model setup can slow the upstream spread of buoyant plumes, they cannot prevent it. In this article, we revisit this problem using a set of numerical experiments. We show that the upstream spreading of buoyant plumes is associated with the geostrophic adjustment of the buoyant discharge, which creates a baroclinic pressure gradient that forces a diversion of the discharge in the upstream direction. We argue, furthermore, that upstream motion is endemic to bottom-trapped plumes and that downstream displacements are associated with the barotropic pressure gradient generated by coastally trapped waves. In an accompanying note (Matano and Palma 2010), we further explore this theme by analyzing the spindown of a bottom-trapped plume. There, we show that, if the buoyancy source is turned off, the downstream velocities reverse direction and the entire density anomaly moves in the upstream direction. These dramatic changes highlight the importance of the baroclinic pressure gradient in plume dynamics. Most importantly, they emphasize the fact that, if the source of barotropic energy is suppressed, a coastally trapped density anomaly will generate an upstream not a downstream motion.

This article is organized as follows: after this introduction, in section 2, we describe the model setup and outline the experiments to be discussed. In section 3, we 


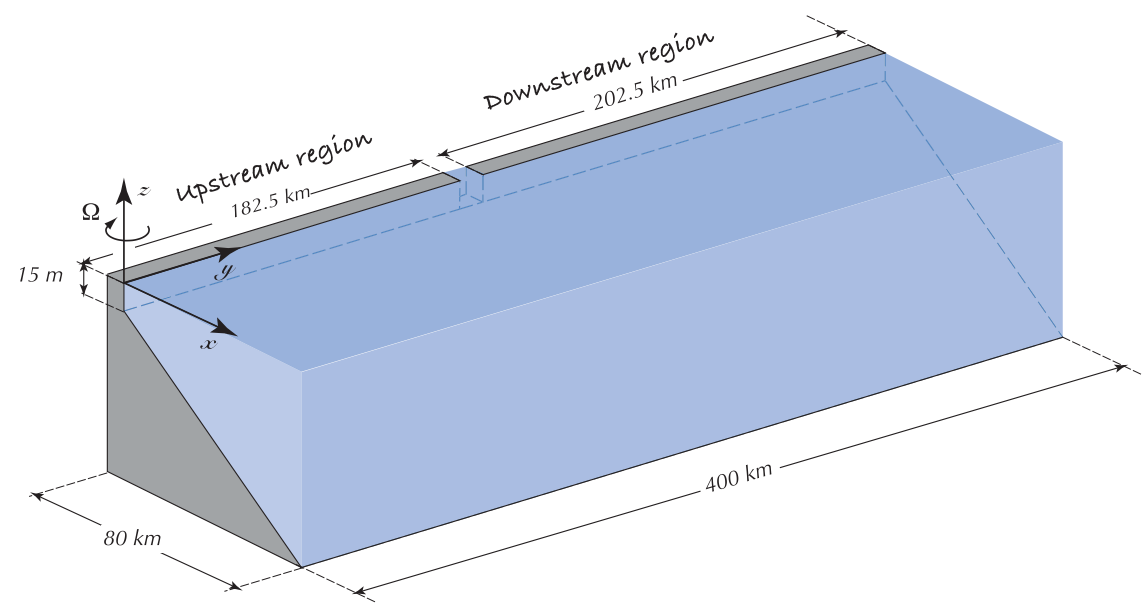

FIG. 2. Domain of the numerical simulations. The sensitivity studies use a similar domain, but with different configurations of the bottom topography. The bottom slopes of the different experiments can be found in Table 1. Note that the domain is set in the Southern Hemisphere (clockwise rotation).

describe the model results, starting with our benchmark case, which is a numerical experiment that does not include the effects of bottom friction, continuing with a sensitivity study of the model parameters. Section 4 contains a final summary and discussion.

\section{Model description}

The numerical model used in this study is the Princeton Ocean Model. The model equations and the numerical algorithms used to solve them have been described in detail by Blumberg and Mellor (1987) and will not be repeated here. The model solves the $3 \mathrm{D}$ primitive equations on an Arakawa $\mathrm{C}$ grid; it uses sigma coordinates in the vertical and curvilinear coordinates in the horizontal. For the purposes of this study, we replaced the prognostic equations for temperature and salinity with a density equation. Horizontal mixing of momentum was parameterized using a Laplacian operator with a mixing coefficient $A_{M}=20 \mathrm{~m}^{2} \mathrm{~s}^{-1}$. Vertical mixing of momentum and tracers was parameterized either with a constant coefficient or the Mellor-Yamada 2.5 turbulence closure model (MY; Mellor and Yamada 1982). A recursive Smolarkiewicz advection scheme is used for the density field (Smolarkiewicz and Grabowski 1990).

The model domain is set in the Southern Hemisphere and consists of a rectangular basin with a 400-km alongshelf extent and $80 \mathrm{~km}$ in the cross-shelf direction (Fig. 2). The model has a horizontal resolution of $2.5 \mathrm{~km}$ in the $y$ (alongshore) direction and $1.25 \mathrm{~km}$ in the $x$ (cross shore) direction and 25 sigma levels in the vertical with enhanced resolution in the surface and bottom layers to properly resolve the vertical structure of surface-advected and bottom-advected plumes. The bottom topography consists of a shelf with constant slope and no along-shelf variations (Fig. 2). Bottom friction is parameterized with a quadratic friction law with a variable drag coefficient (Blumberg and Mellor 1987). The southern, northern, and eastern sides of the domain are open boundaries where we impose the conditions recommended by Palma and Matano (1998, 2000). The western boundary is closed, except for the buoyant discharge through the inlet where we impose a freshwater source in the continuity equation following the scheme of Kourafalou et al. (1996). The freshwater discharge has a density anomaly of $-1 \mathrm{~kg} \mathrm{~m}^{-3}$ and a fixed discharge rate of $Q_{r}=$ $24000 \mathrm{~m}^{3} \mathrm{~s}^{-1}$. The upstream edge of the inlet is located at $y=195 \mathrm{~km}$, and its width is $L=17.5 \mathrm{~km}$ (Fig. 2).

Table 1 lists the characteristics of the experiments discussed in this article. In the benchmark case (EXP1), the ocean is initially quiescent with a constant reference density $\rho_{0}$, the Coriolis parameter is set at $f=-1.0 \times$ $10^{-4} \mathrm{~s}^{-1}$, and the coefficients of vertical eddy viscosity $K_{M}$ and diffusivity $K_{H}$ are computed using the MY closure scheme. Ocean depth is $15 \mathrm{~m}$ at the coast and increases linearly cross-shore with bottom slope $\alpha=2 \times 10^{-3}$. The buoyant discharge is held constant through the 30 days of model run, which is long enough for the development of the downstream and upstream spreading. The appendix shows the terms of the momentum balance equation used in the discussion.

\section{Results}

To simplify the interpretation of the numerical results, we start by reducing the problem to its bare essentials, 
TABLE 1. Characteristics of the numerical experiments described in the text.

\begin{tabular}{lccccc}
\hline \hline & $\begin{array}{c}\text { Bottom } \\
\text { slope }\end{array}$ & $\Delta \rho$ & $\begin{array}{c}\text { Vertical } \\
\text { mixing }\end{array}$ & $\begin{array}{c}\text { Bottom } \\
\text { boundary } \\
\text { condition }\end{array}$ & Inlet \\
\hline EXP1 & $2 \times 10^{-3}$ & -1.0 & MY & Slip & Simple \\
EXP2 & $2 \times 10^{-3}$ & -1.0 & MY & Nonslip & Simple \\
EXP3 & $1 \times 10^{-3}$ & -1.0 & MY & Nonslip & Simple \\
EXP4 & $3 \times 10^{-3}$ & -1.0 & MY & Nonslip & Simple \\
EXP5 & $1 \times 10^{-2}$ & -1.0 & MY & Nonslip & Simple \\
EXP6 & $H=30 \mathrm{~m}$ & -1.0 & MY & Nonslip & Simple \\
EXP7 & $H=70 \mathrm{~m}$ & -1.0 & MY & Nonslip & Simple \\
EXP8 & $H=70 \mathrm{~m}$ & 0 & MY & Nonslip & Simple \\
EXP9 & $H=70 \mathrm{~m}$ & +1.0 & MY & Nonslip & Simple \\
EXP10 & $H=70 \mathrm{~m}$ & +1.0 & MY & Nonslip & Estuary N \\
EXP11 & $H=70 \mathrm{~m}$ & +1.0 & MY & Nonslip & Estuary S \\
\hline
\end{tabular}

using a benchmark experiment without bottom friction (EXP1; Table 1). In this case, the condition at the bottom boundary is

$$
\frac{\partial U}{\partial z}=0 \quad \text { at } \quad z=0
$$

which prevents the development of a bottom boundary layer (BBL) and the cross-shelf circulation associated with it (e.g., Matano and Palma 2008). The effects of bottom friction will be discussed in some detail in section $3 \mathrm{~b}$.

\section{a. The benchmark experiment}

The benchmark experiment was started from rest and integrated for 30 days. To characterize the spinup, we computed the Hovmöller diagram of the minimum surface density at each cross-shelf section (Fig. 3). As seen in previous studies, after its release the buoyant discharge not only spreads in the downstream direction but also in the upstream direction. The rate of downstream spreading $\left(\sim 15 \mathrm{~cm} \mathrm{~s}^{-1}\right)$ is $4-5$ times faster than the rate of upstream spreading $\left[\sim(3-4) \mathrm{cm} \mathrm{s}^{-1}\right]$, but the latter is a persistent phenomenon. In fact, in long integrations the density anomaly extends through both ends of the domain. The importance of this phenomenon is highlighted by the fact that while the total upstream volume flux is almost nil the upstream freshwater transport is close to that of the downstream region (Fig. 4); that is, the upstream current diverts approximately half of the total freshwater input onto the shelf, thus significantly weakening the downstream influence of the discharge. Here, the freshwater flux is calculated as (e.g., Fong and Geyer 2002; Narayanan and Garvine 2002)

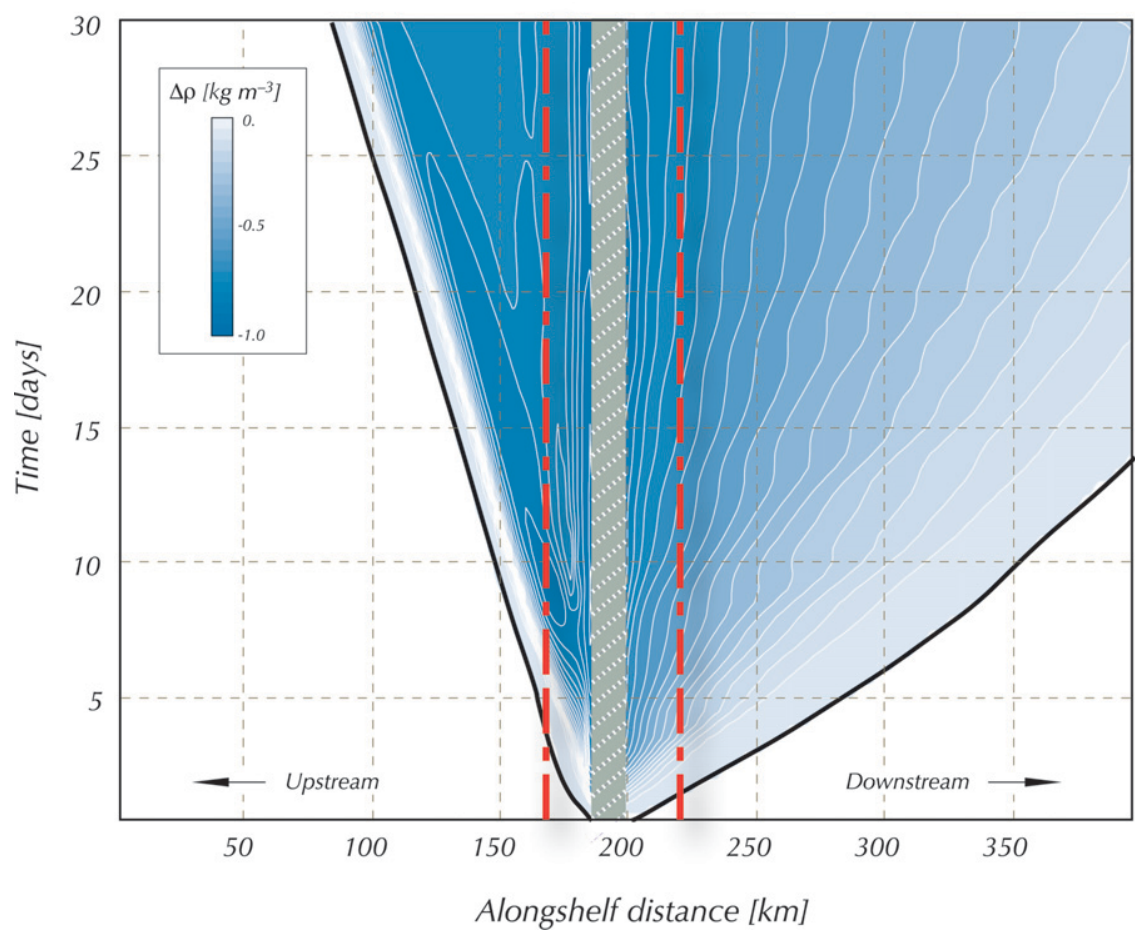

FIG. 3. Hovmöller diagram of the minimum surface density at each cross-shelf section. The crosshatch marks the location of the outflow discharge, and the dotted lines mark the locations of the two cross sections where the flow is evaluated. 


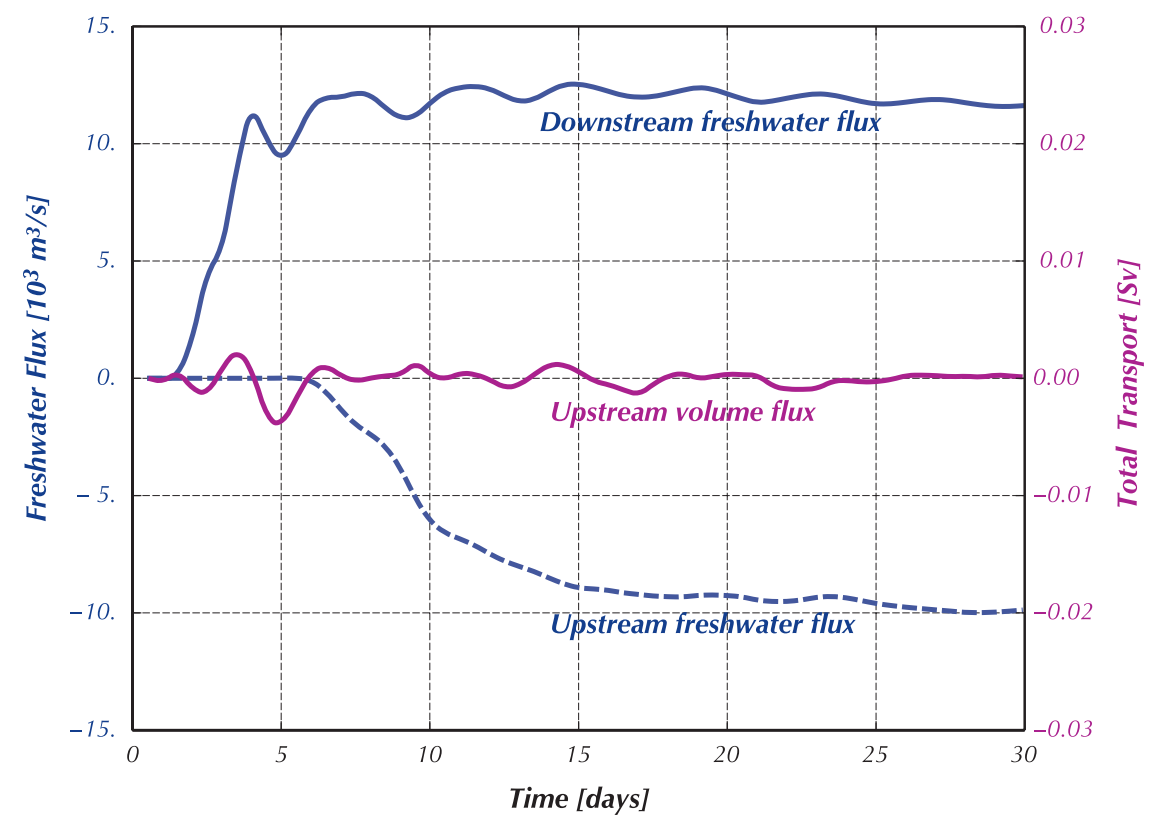

FIG. 4. Time series of the volume and freshwater fluxes at the upstream and downstream cross sections. The definitions can be found in the text. See Figs. 3 and 5 for locations of the cross sections.

$$
Q_{\mathrm{fw}}=\int_{-h}^{0} \int_{0}^{\infty} v \frac{\left(\rho-\rho_{o}\right)}{\rho_{o}} d x d z
$$

To describe the evolution of the plume, we will first discuss the first 10 days of the numerical simulation, which encompass the period in which the plume extends through the cross sections selected for the analysis and the upstream flow is established. After day 10, the changes of the along-shelf velocities are relatively small, but the cross-shelf circulation continues evolving. By day 15 , the structure of the flow in the selected cross-shelf locations is largely established and the differences with the flow at the end of the simulation are qualitatively insignificant (e.g., Fig. 4).

The state of the plume at day 10 is characterized with snapshots of the surface density anomalies and sea surface heights (SSHs; Fig. 5). Initially, the discharge spreads isotropically around the inlet until the scale of the perturbation grows so that rotation effects become important. After this, the dynamical adjustments over the northern and southern portions of the shelf follow quite different paths. The downstream adjustment starts with the generation and propagation of barotropic coastally trapped waves, traveling with the coast to their left (e.g., Brink 1991). These waves traverse the domain in less than two days, leaving in their wake a cross-shelf SSH gradient with a geostrophically adjusted along-shelf current. This current advects the density anomaly trailing the SSH signal. The time disparity between the barotropic and the baroclinic adjustment is reflected in the snapshots of the SSH and density anomalies, which show the former leading the latter (Fig. 5). The downstream advection of the buoyant discharge changes the barotropic pressure field and leads to a new dynamical equilibrium of the along-shelf current. After 10 days of model simulation, the downstream cross-shelf momentum balance of the vertically integrated flow shows that the along-shelf current (Coriolis term in Fig. 6) is balanced by the difference between the barotropic pressure gradients set up by the coastally trapped waves and the baroclinic pressure gradient generated by the density advection (Fig. 6; appendix). The along-shelf density gradient generated by the downstream spreading of the plume generates a crossshelf circulation pattern that is in thermal wind balance. Thus, for $\partial \rho / \partial y>0, \partial U / \partial z<0$ and the cross-shelf circulation consists of an offshore flow of low-density waters at depth and an onshore flow of high-density waters at the surface. This hydrostatically unstable circulation pattern leads to vigorous vertical mixing in the downstream region and to the formation of the distinct cross-shelf density structure that is typically associated with bottom-trapped plumes (Fig. 7).

In the next paragraph, we will describe in detail the sequence of events that leads to the upstream spreading in the numerical experiment. First, however, we would like to outline the basic spreading mechanism (Fig. 8). To this end, first consider an arbitrary equilibrium state in which the upstream transport along the coast is 


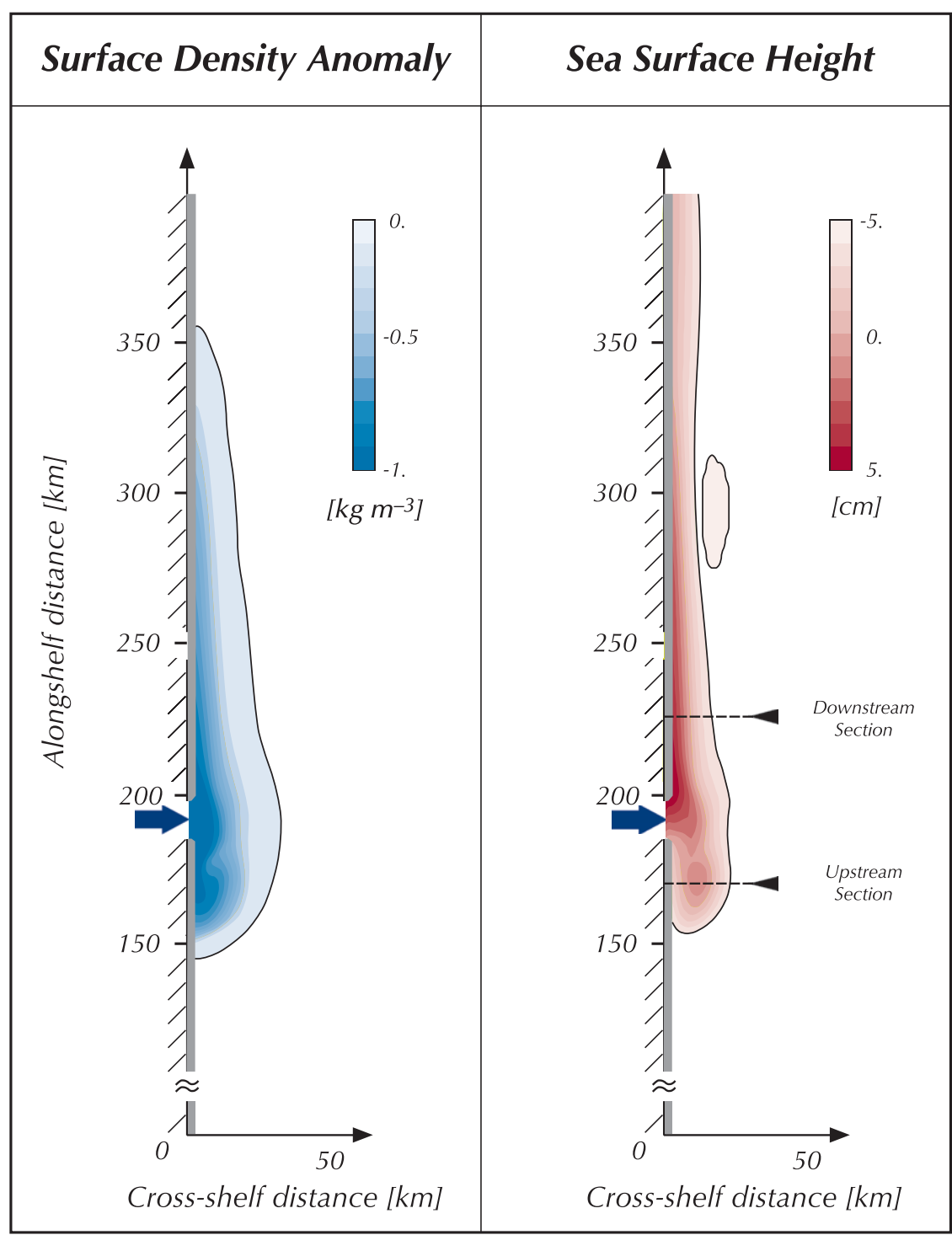

FIG. 5. Snapshots of (left) surface density anomaly and (right) SSH at day 10 in EXP1 (Table 1). For the purpose of display, the domain was truncated in the lower half. The blue arrow marks the location of the inlet, and the black lines with arrowheads in the SSH snapshot mark the location of the downstream and upstream cross sections that are used in the analysis. Units are kilograms per meter cubed for the density plot and centimeters for the SSH.

compensated by an equivalent downstream transport farther offshore (Fig. 8a). This balance state does not require nor allow a farther upstream excursion of the plume. The upstream advance is produced by the alongshelf advection of fresher waters from the inlet (Fig. 8b). As these waters move toward the nose, they augment the cross-shore baroclinic pressure gradient $(\partial \rho / \partial x)$ and therefore the upstream geostrophic velocities associated with them $(V \sim-\partial \rho / \partial x)$; that is, the transport at point $\mathrm{A}$ becomes larger than the transport at point $\mathrm{B}$ and the plume moves farther upstream (Fig. 8c), where the process repeats itself. Thus, the upstream progression of the buoyant plume is driven by the baroclinic pressure gradient generated by the negative density anomaly advected along the coast. This gradient tends to generate upstream flows in both the upstream and the downstream region, but in the latter its upper-layer effect is overpowered by the barotropic pressure gradient generated by the coastally trapped waves. In the upstream region, however, where barotropic energy cannot be propagated by coastally trapped waves, the baroclinic pressure gradient effectively drives upstream flow. The different roles played by barotropic and baroclinic processes in the development of the plume in the downstream and upstream 


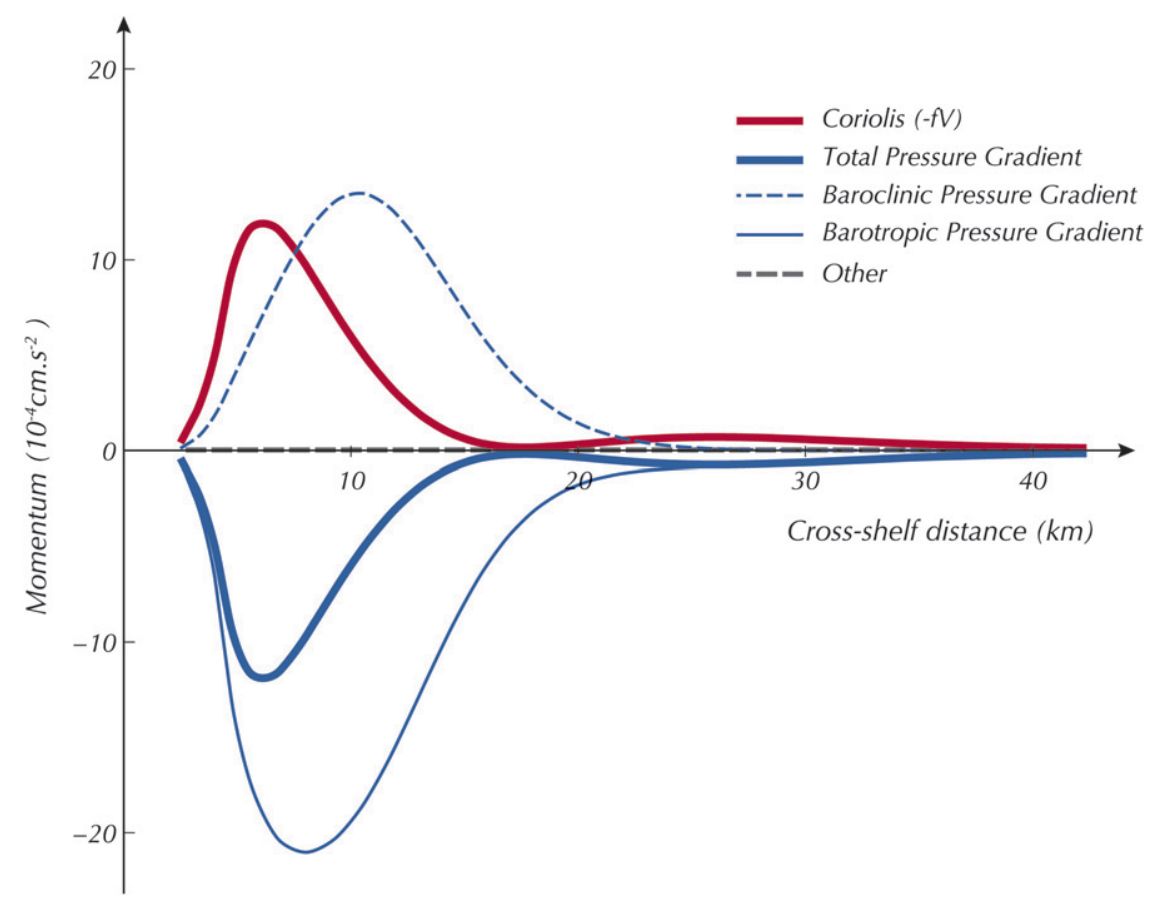

FIG. 6. Cross-shelf component of the vertically averaged momentum balance in the downstream cross section at day 10. See Fig. 5 for the location of the cross section.

regions are reflected in Fig. 5, showing that SSHs lead the sea surface densities in the downstream region but not in the upstream region.

To characterize the upstream spreading in the numerical simulation, let us consider the evolution of the flow in the upstream cross section, which begins at day 4 (Fig. 9). At this time, the density anomaly is confined to the uppermost layer and has no dynamical influence. Therefore, the cross-shelf circulation is controlled by the along-shelf barotropic pressure gradient $(\partial \eta / \partial y>0)$, which produces a surface-to-bottom offshore flow with a consequent drop of the SSH near the coast (i.e., $\partial \eta / \partial x>0$ ). Through geostrophic equilibrium, this cross-shelf SSH gradient generates a barotropic upstream flow in the inshore region that advects the density anomaly farther upstream. The baroclinic development of the flow starts at day 5 and reaches a mature stage at day 10 (e.g., Fig. 4). The advance of the density anomaly produces a profound change in the vertical structure of the cross-shelf flow (Fig. 10). Through thermal wind, the newly developed along-shelf density gradient $(\partial \rho / \partial y<0)$ generates a vertical shear of the cross-shelf flow $(\partial U / \partial z>0)$, which by day 10 reverses the direction of the surface flow in the deep layers (Fig. 10). Bottom water now moves upslope, displacing the density minimum offshore and creating a distinct crossshelf density structure that contrasts markedly with that of the downstream region (e.g., cf. day 10 in Fig. 10 with Fig. 7). These contrasts reflect the opposite signs of the along-shelf density gradients, which through thermal wind equilibrium generate a hydrostatically unstable downslope flow in the downstream region and a hydrostatically stable upslope flow in the upstream region. Thus, the advance of a plume homogenizes the downstream region and stratifies the upstream region. The feedback between the density and velocity fields is clearly reflected in the evolution of the upstream velocities (Fig. 10, bottom). The along-shelf velocity field is very weak at day 6 , when the density anomaly starts to appear, but is fully developed by day 10 , when the density anomaly reaches a more mature state. During this period, the inshore (upstream) portion of the current is stronger than the offshore (downstream) portion, indicating that the plume is moving upstream (e.g., Fig. 8b). Note the double maximum of the along-shelf velocities at day 10: one in the upper layer of the inshore region and the other in the bottom layer farther offshore. As we shall show, the former is driven by the SSH drop near the coast (barotropic pressure gradient), whereas the latter is driven by the cross-shelf density differences (baroclinic pressure gradient).

The cross-shelf momentum balance quantifies the contribution of barotropic and baroclinic processes to the development of the along-shelf flow (Fig. 11). The upstream flow in the innermost region $(x<5 \mathrm{~km})$ is largely driven the barotropic pressure gradient associated with the positive SSH slope near the coast (cf. Fig. 5). As 

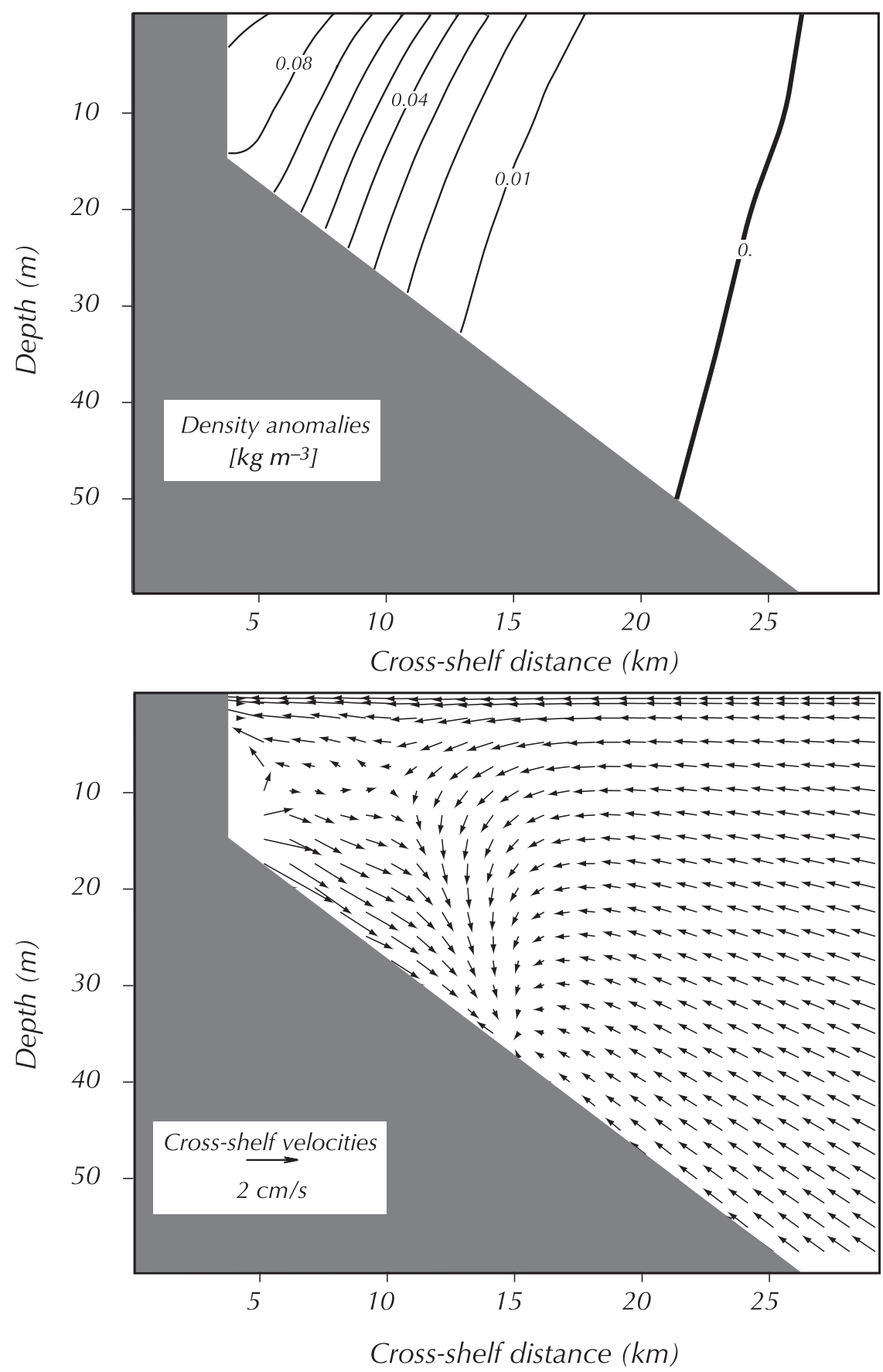

FIG. 7. (top) Density anomalies and (bottom) cross-shelf velocity vectors in the downstream cross section at day 10 . Units are kilograms per meter cubed for density and centimeters per second for velocities. See Fig. 5 for the location of the cross section.

noted earlier, this slope is driven by the along-shelf pressure gradient, which flushes surface water offshore and entrains deep waters onshore (Fig. 11). The onshore flow of denser water generates a negative cross-shelf density gradient $(\partial \rho / \partial x<0 ;$ Fig. 10) in the inner-shelf $(x<5 \mathrm{~km})$ and therefore a baroclinic pressure gradient that opposes the upstream spreading of the flow (Fig. 11). The magnitude of the baroclinic pressure gradient increases with depth, and by day 10 it has generated a bottom downstream current along the coast (Fig. 10). The upslope flow displaces the density minimum offshore and therefore the peak of the depth-averaged upstream flow is at 

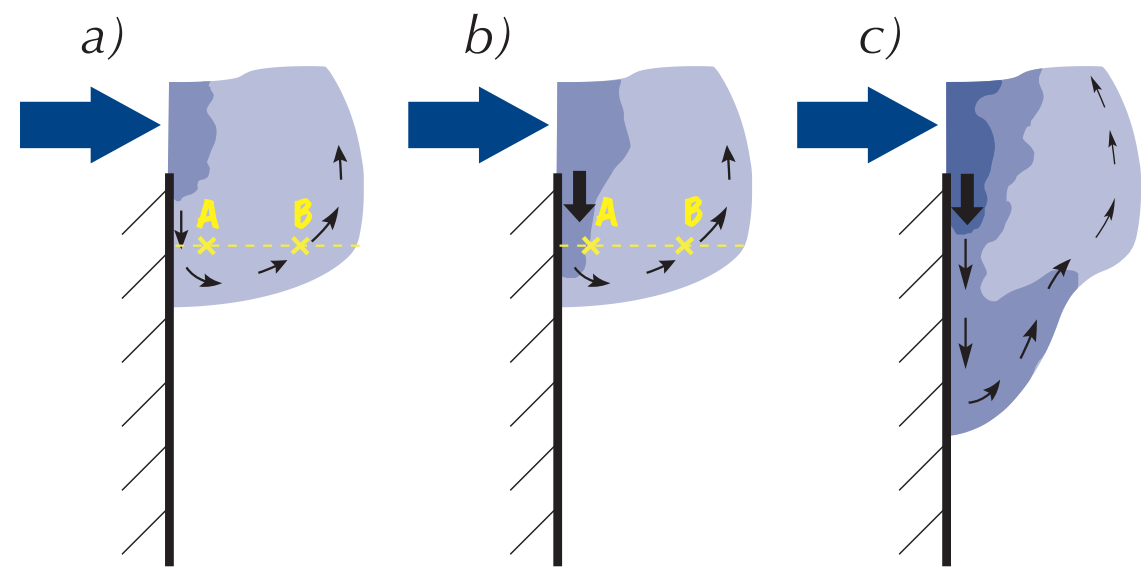

FIG. 8. Schematic of the upstream advance of a buoyant plume. (a) Arbitrary equilibrium state in which the upstream flow at point $\mathrm{A}$ is compensated by a similar downstream flow at point B. (b) The inshore (upstream) velocities advect fresher water from the inlet. This causes an increase of the baroclinic pressure gradient and hence the upstream velocities. At this stage, the upstream transport in point $\mathrm{A}$ is larger than the downstream transport in point B. (c) As result of the imbalance, the plume moves upstream, where the process repeats itself.

approximately $x=10 \mathrm{~km}$, where the barotropic and baroclinic pressure gradients reach their maximum inphase contribution (Fig. 11). The offshore extension of the upstream current is determined by the cross-shelf gradient of the $\mathrm{SSH}$, which ebbs at approximately $12 \mathrm{~km}$ from the coast (Fig. 11). The baroclinic pressure gradient keeps increasing farther offshore, but this increase is compensated by a corresponding decrease of the barotropic pressure gradient, which now leads to the development of a downstream flow. It is obvious from the cross-shelf momentum balance that the density anomaly not only strengthens the inshore-upstream portion of the flow but also weakens the offshore-downstream portion of it. Its overall effect therefore is to foster the advance of the plume in the upstream direction.

The development of the cross-shelf circulation peaks at approximately day 10 , which is the approximate time that it takes the density front to pass through the upstream cross section (Fig. 3). After that, the flow evolves to a final equilibrium in which the recirculation cell described earlier is replaced by an offshore flow in the inner shelf region (Fig. 10, day 15). This change is a consequence of the waning of the along-shelf density gradient (and hence the vertical shear of the cross-shelf velocity) that follows the passage of the front (Fig. 12). Thus, after the passage of the plume's nose, $\partial \rho / \partial y$ decreases to the point where it can no longer sustain a reversal of the surface velocities driven by the along-shelf gradient of SSH. Our experiment shows an increase of the crossshelf velocities with depth that is associated with the development of a secondary circulation; the secondary circulation produces upwelling and hence a relatively minor bump in $\partial \rho / \partial y$ in the upstream cross section (white stippled line in Fig. 12, top). This bump disappears in experiments with bottom friction (Fig. 12, bottom). The final equilibrium of the density and along-shelf velocities shows relatively small changes with respect to those of day 10 (Fig. 10), the most significant of which are the disappearance of the surface velocity maximum related to the onshore flow in the deep layers and the encroachment of the density minimum on the coast. Thus, the equilibrium along-shelf velocities have a maximum in the bottom layer, reflecting their baroclinic origin (Fig. 10). As we shall show in the next section, this structure is not likely to be observed in the real ocean because of frictional effects. The changes in the cross-shelf circulation after the passage of the density front are less radical in the downstream region and consist mostly of a reduction of the cross-shelf velocities.

In summary, the evolution of the upstream spreading of the buoyant flow is as follows: First, the buoyant discharge generates an along-shelf pressure ( $\mathrm{SSH}$ ) gradient with an upstream current near the coast that is balanced by a downstream current farther offshore. If the discharge is entirely barotropic (i.e., no density anomaly), the evolution of the upstream flow stops there. However, a buoyant anomaly will be advected along the coast by the upstream flow and generate a positive baroclinic pressure gradient that strengthens the upstream (inshore) current and weakens the downstream (offshore) current, thus advecting the density anomaly farther upstream in a selfsustaining motion. As noted before, the baroclinic pressure gradient tends to generate upstream flows in both the upstream and downstream regions, but in the latter its 


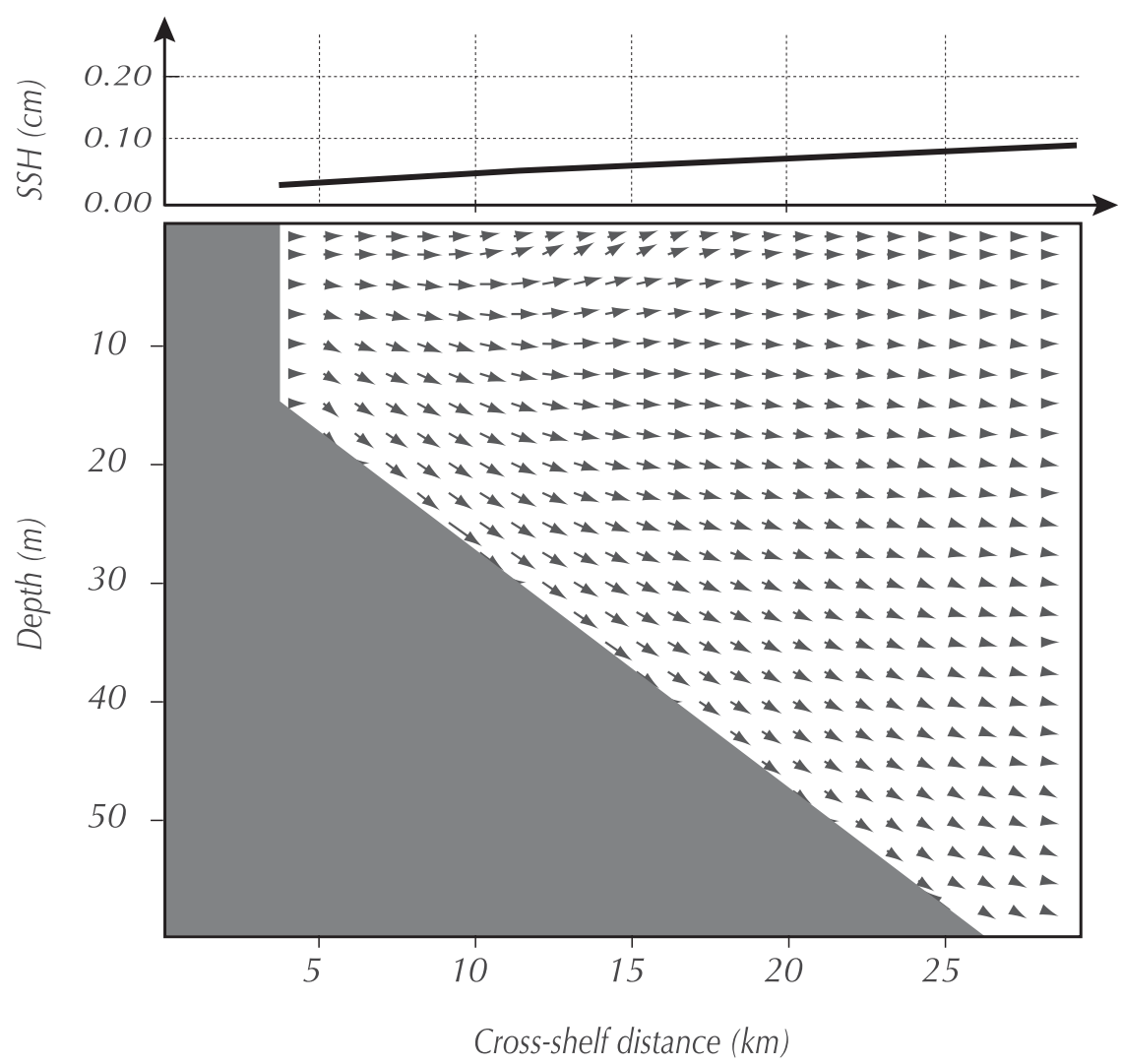

FIG. 9. (top) Cross-shelf distribution of SSH at day 4 in the upstream cross section. (bottom) Cross-shelf velocity vectors at day 4 in the upstream cross section. Units are $\mathrm{cm}$ for SSH and $\mathrm{cm} \mathrm{s}^{-1}$ for velocities. See Fig. 5 for the location of the cross section.

upper-layer effect is overpowered by the barotropic pressure gradient generated by the coastally trapped waves. The baroclinic pressure gradient nevertheless drives an upstream flow in the downstream region; it generates a deep countercurrent underneath the upper-layer downstream flow (Fig. 13a). The cross-shelf momentum balance in the bottom layer effectively shows that this countercurrent is driven by the baroclinic pressure gradient (Fig. 13b). Chapman and Lentz (1994) attributed the development of such countercurrent to the offshore spreading of the plume by frictional effects. Our experiments indicate that this is not necessarily the case, because the deep undercurrent will develop even if the model does not include bottom friction; that is, the deep undercurrent is not caused by the frictionally driven offshore displacement of the plume but rather by its crossshelf density gradient. The balance between the pressure gradients associated with the SSH and the cross-shelf density difference determines the location of the front separating the surface (downstream) and bottom (upstream) currents.

In an accompanying note, we further explore the role of the baroclinic pressure gradient in the development of upstream flows by investigating the spindown of a bottomtrapped plume (Matano and Palma 2010). There, we show that without buoyancy forcing at the inlet the dynamics of the upstream and the downstream regions is controlled by the baroclinic pressure gradient. Thus, if the buoyancy discharge is removed, the downstream velocities reverse direction and the entire density anomaly moves in the upstream direction, leaving the domain through the upstream boundary. The dramatic changes observed in the spindown experiment highlight the importance of the baroclinic pressure gradient in the plume dynamics. Most importantly, it emphasizes the fact that the downstream spreading of a plume is entirely a barotropic phenomenon: if the source of barotropic energy is suppressed, a buoyant density anomaly will move in the upstream direction, not the downstream direction.

\section{b. Sensitivity studies}

Although upstream spreading is a robust characteristic of bottom-trapped plumes, the bottom friction, topographic slope, and magnitude of the density anomaly all influence the spreading rate and thermohaline structure 

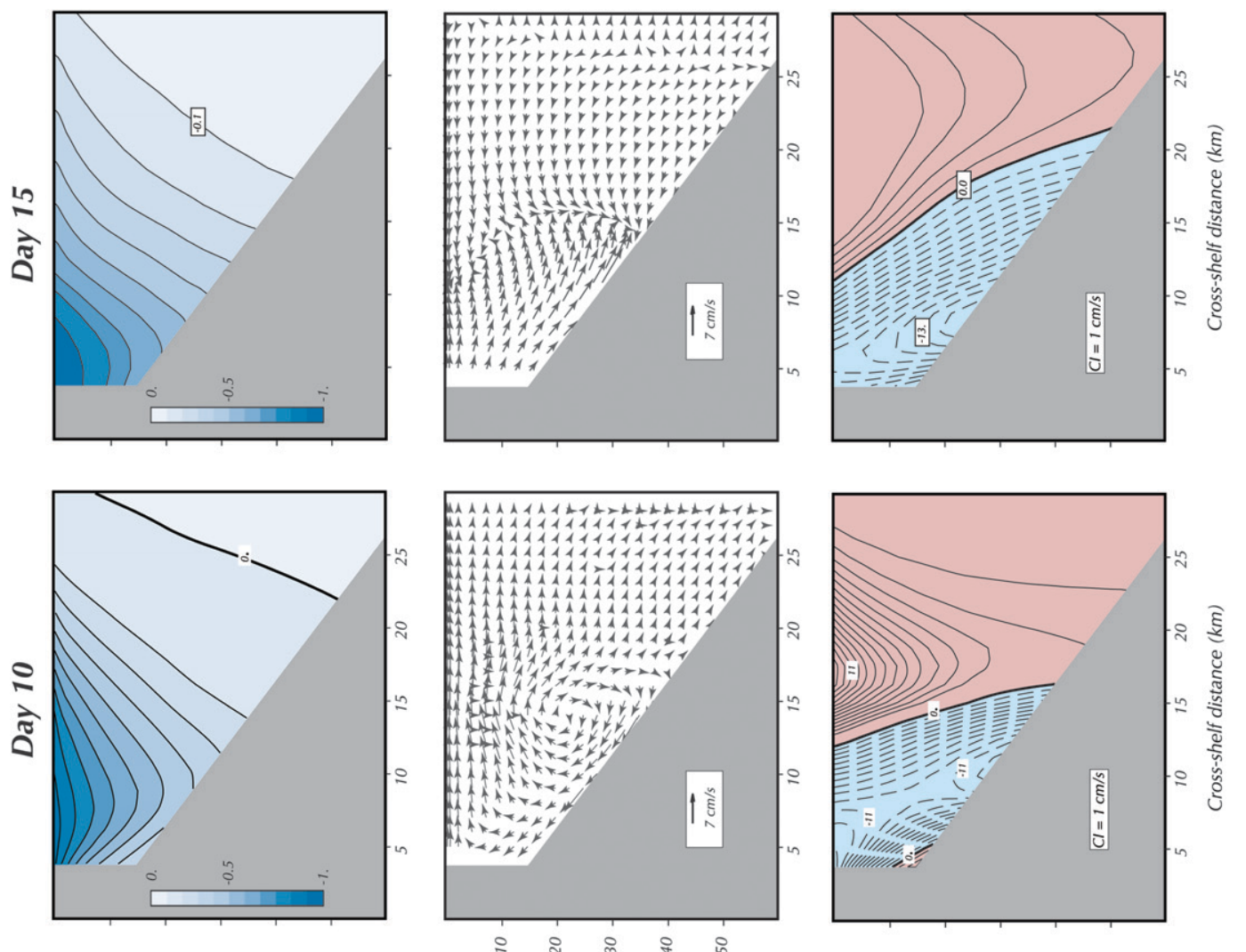

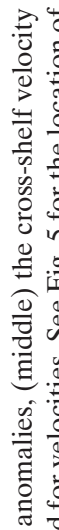
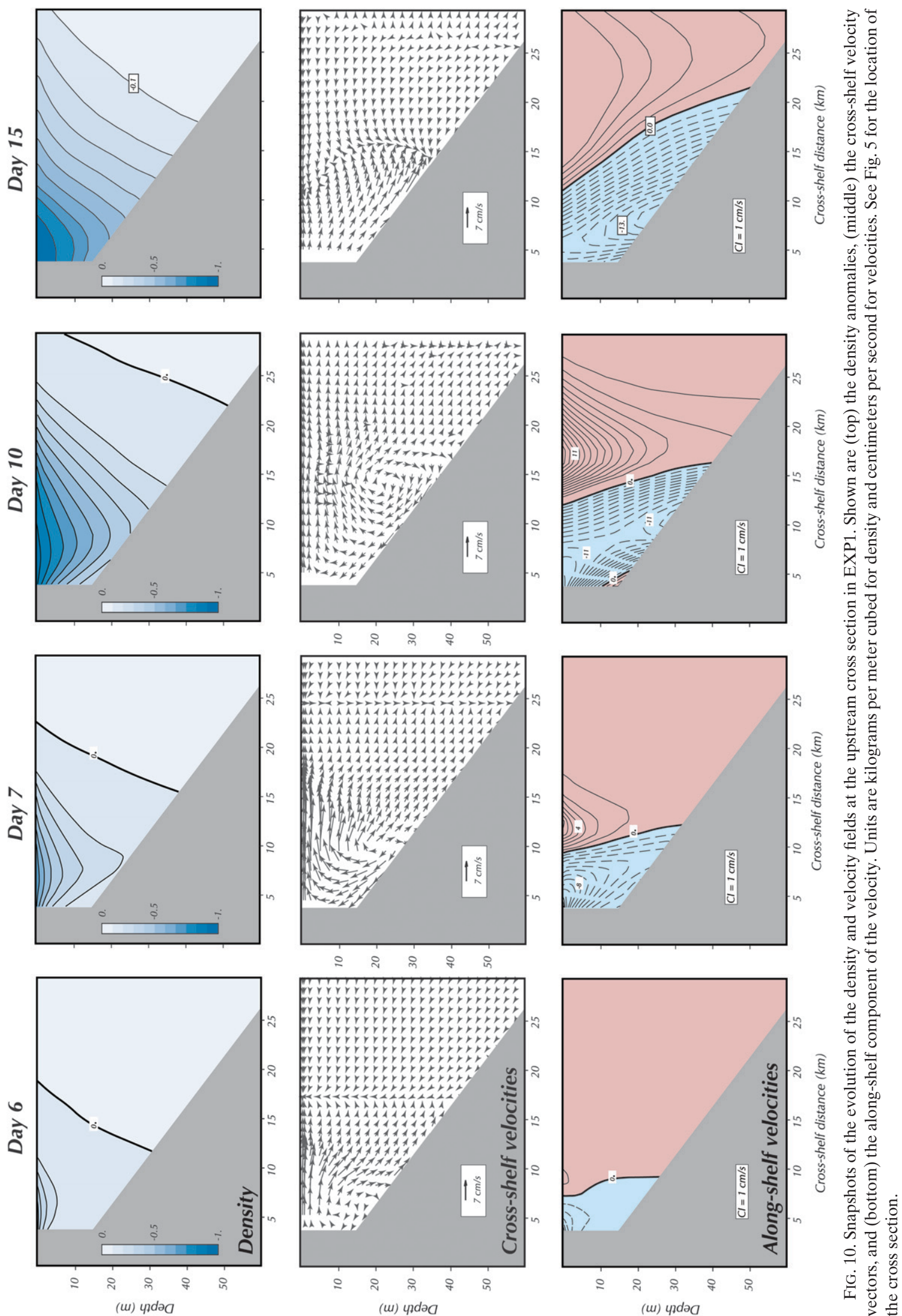


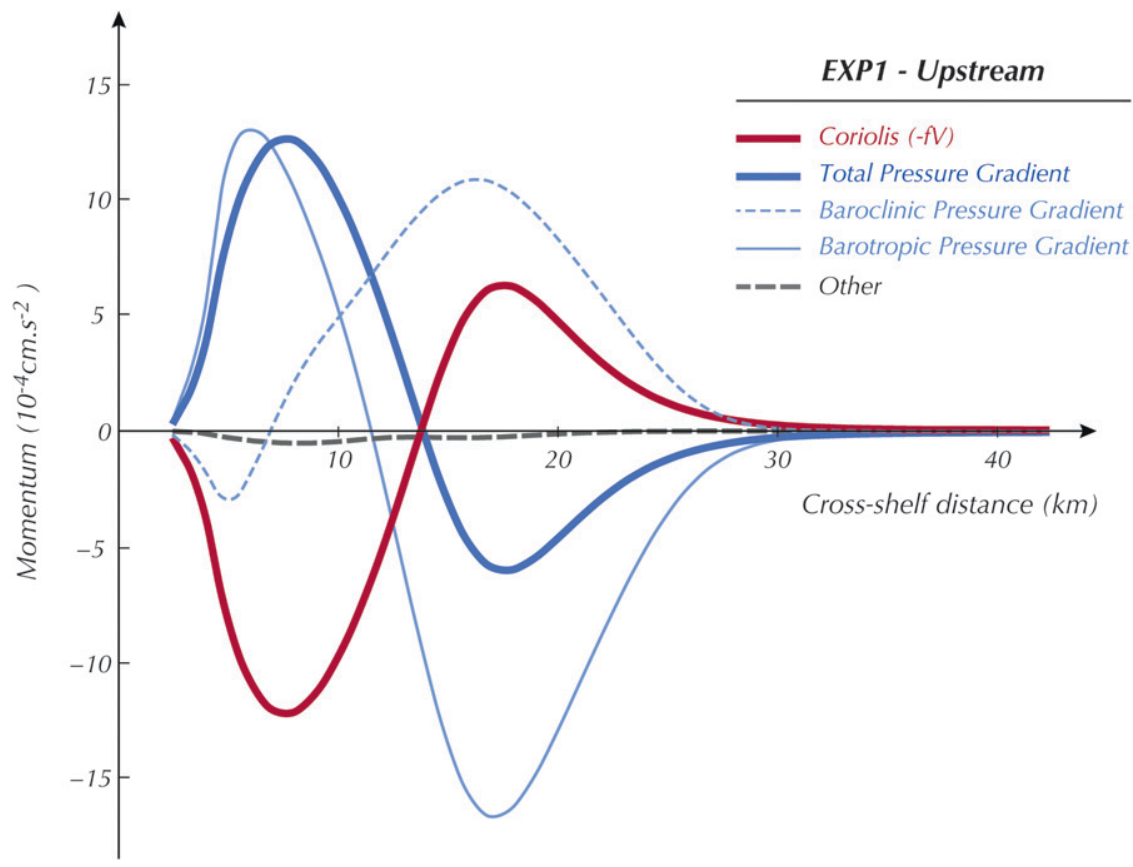

FIG. 11. Cross-shelf component of the vertically averaged momentum balance in the upstream cross section at day 10 for EXP1 (Table 1). See Fig. 5 for the location of the cross section.

of the plume. In this section, we present a brief discussion of these matters.

We used an experiment without bottom friction to emphasize the fact that the cross-shelf circulation patterns generated by the buoyant discharge do not depend on the BBL dynamics but rather on the thermal wind balance. What matters for the development of upstream spreading is the magnitude of the density anomaly and not the
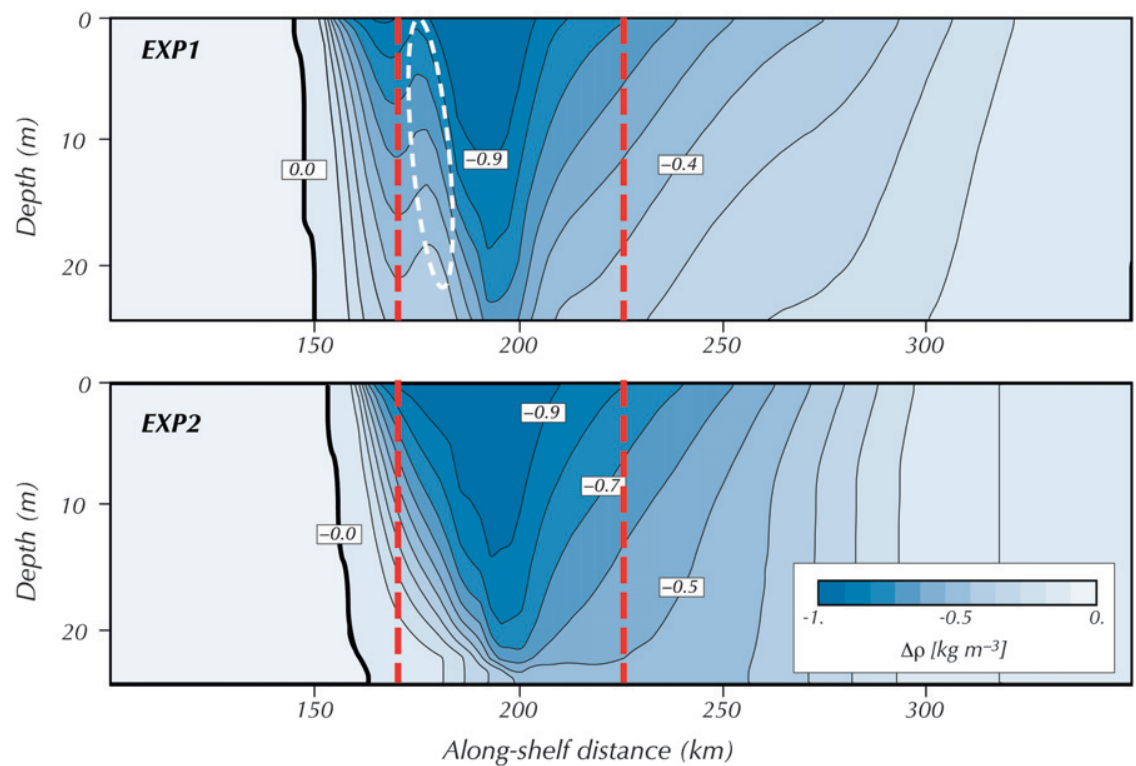

FIG. 12. Snapshots at day 10 of the along-shelf density anomalies at $x=10 \mathrm{~km}$ for (top) EXP1 and (bottom) EXP2. For display purposes, the left side of the domain was truncated for at $y=$ $100 \mathrm{~km}$. The thick dashed lines mark the locations of the upstream and downstream cross sections. Contour interval is $-0.1 \mathrm{~kg} \mathrm{~m}^{-3}$. Table 1 lists the general characteristics of each of these experiments. 
a)

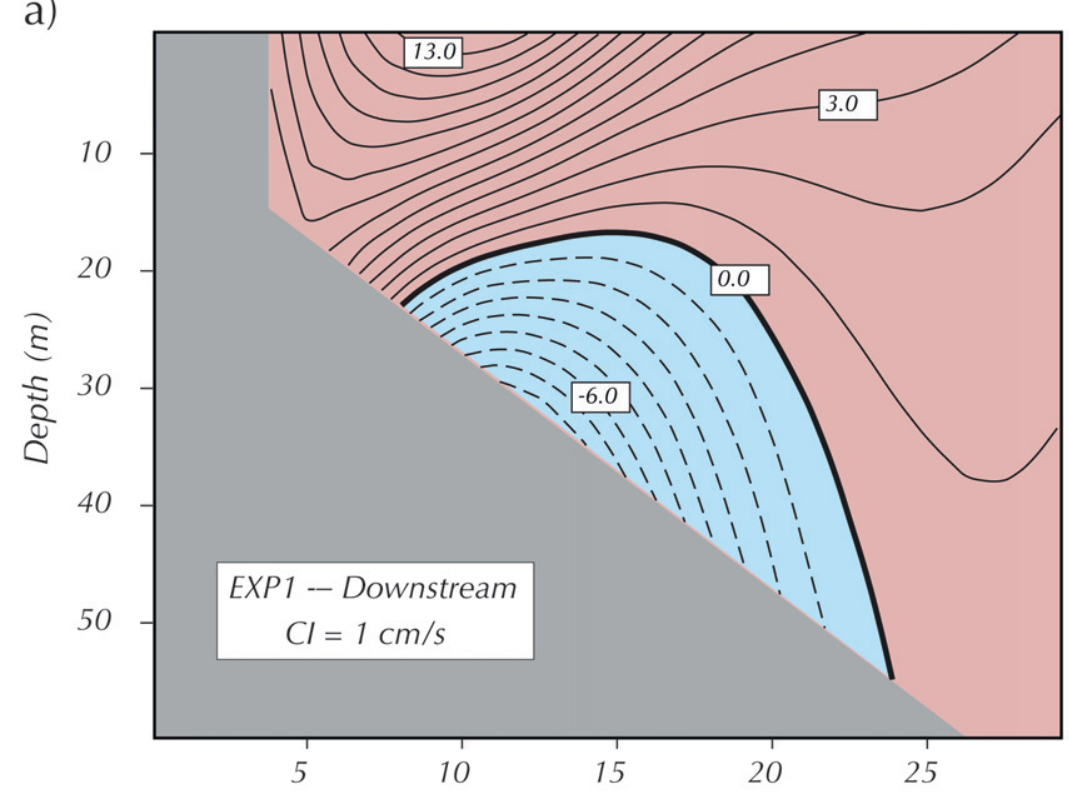

b)

EXP1 - Downstream (BBL)

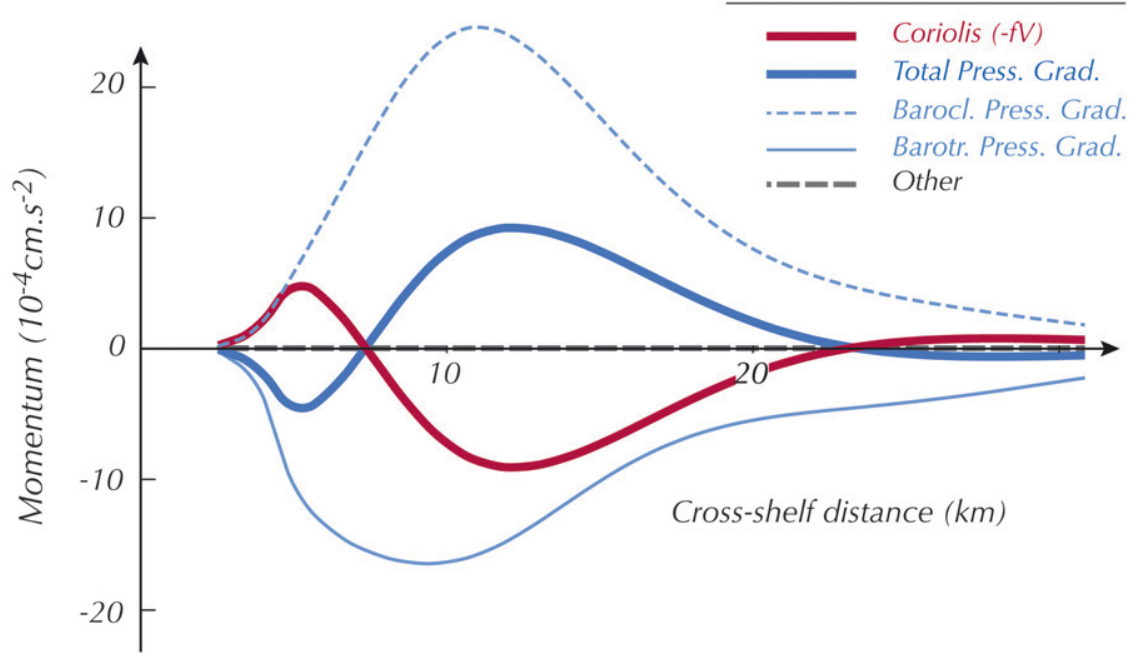

FIG. 13. (a) Along-shelf velocities in the downstream region at day 30 for EXP1. Stippled lines and blue colors correspond with upstream velocities. (b) Cross-shelf component of the momentum balance in the bottom layer. See Fig. 5 for the location of the cross section.

bottom friction coefficient. Bottom friction, nevertheless, plays two important roles in the development of buoyant plumes. First-and most obvious-it draws energy from the mean flow, so that plumes with frictional effects progress less rapidly than those without. Second-and most important-bottom friction reinforces the crossshelf circulation patterns developed during the spinup, and in doing so it influences the final density structure of the flow. Thus, experiments including bottom friction exhibit a more homogeneous downstream region and a more stratified upstream region. To illustrate these effects, we repeated the benchmark experiment including bottom friction (EXP2; Table 1).

The inclusion of bottom friction leads to the development of a BBL and secondary cross-shelf circulation cells that reinforce those generated by the thermal wind balance. For example, the Ekman offshore flow in the downstream region reinforces the preexisting cross-shelf circulation driving light water underneath dense waters and leading to more overturning and consequently to 


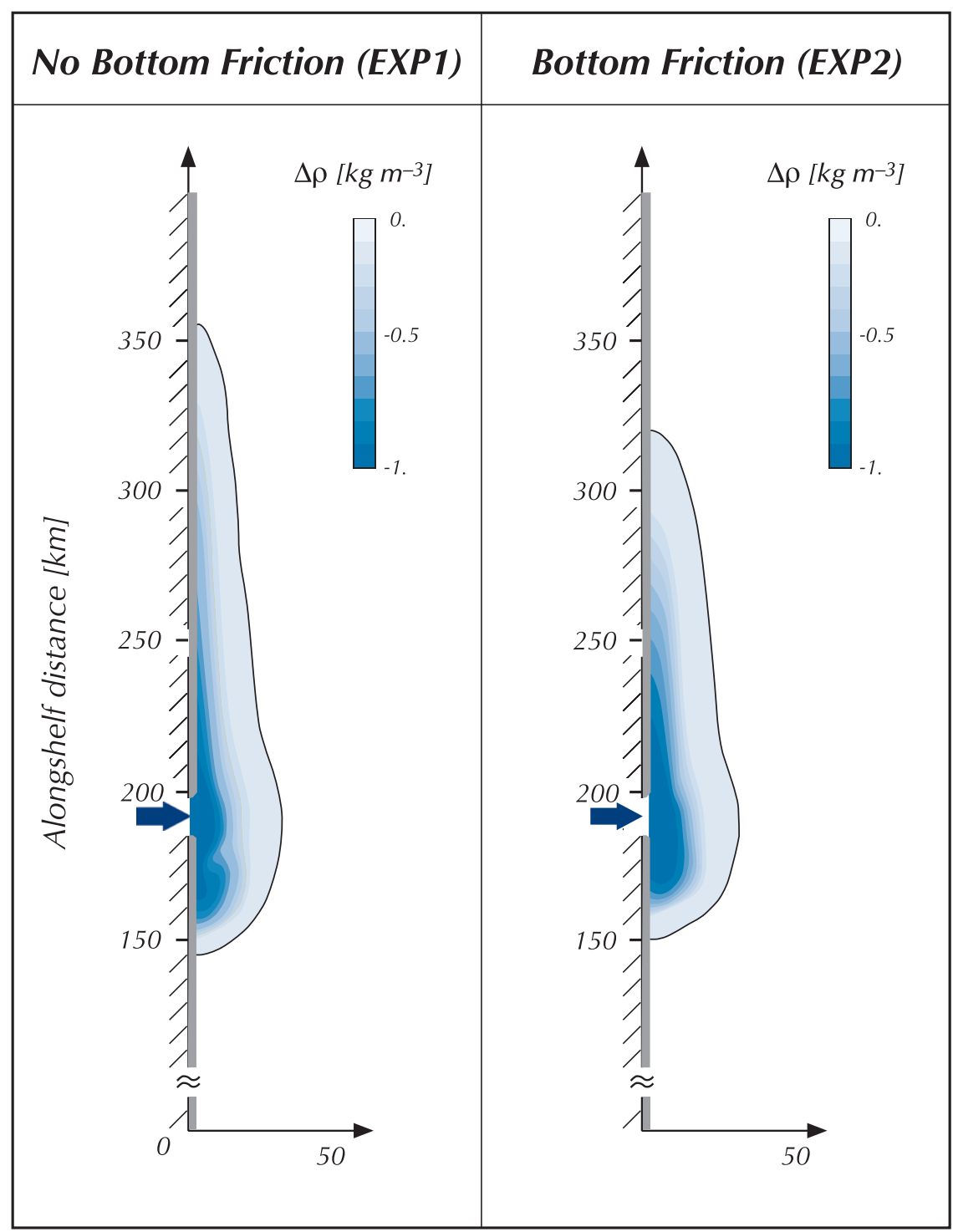

FIG. 14. Sea surface density anomalies $\left(\mathrm{kg} \mathrm{m}^{-3}\right)$ at day 10 for (left) EXP1 (no bottom friction) and (right) EXP2 (bottom friction; Table 1).

a larger homogenization of the water column. Likewise, the Ekman onshore flow in the upstream region reinforces the upslope flow of denser water and strengthens the static stability of the inner shelf. The overall effect of these BBL flows is to increase the homogenization of the downstream region and strengthen the stratification of the upstream region. Thus, along-shelf density sections show that the slanted isopycnals of the downstream region in EXP1 become nearly vertical lines in EXP2, whereas the widely spaced contours of the upstream region in EXP1 are tightly packed in EXP2 (Fig. 12). The second effect of bottom friction is to slow the spreading rate of the buoyant anomaly (Fig. 14). There is an appreciable decrease in the along-shelf spreading of the plume (in both directions) associated with the inclusion of bottom friction. Ancillary experiments (not shown), indicate that the magnitude of the decrease is largely independent of the magnitude of the bottom friction coefficient; instead, it depends on the magnitude of the vertical mixing coefficient.

Sensitivity experiments with various forms of bottom topography (EXP3-EXP7) indicate that, although the downstream spreading rate is proportional to the slope of the bottom topography, the upstream spreading rate is not (Fig. 15). We do not have a clear explanation for this result, but it may reflect the fact that upstream spreading rates are relatively small and therefore variations are difficult to gauge. To investigate the spreading of a plume 


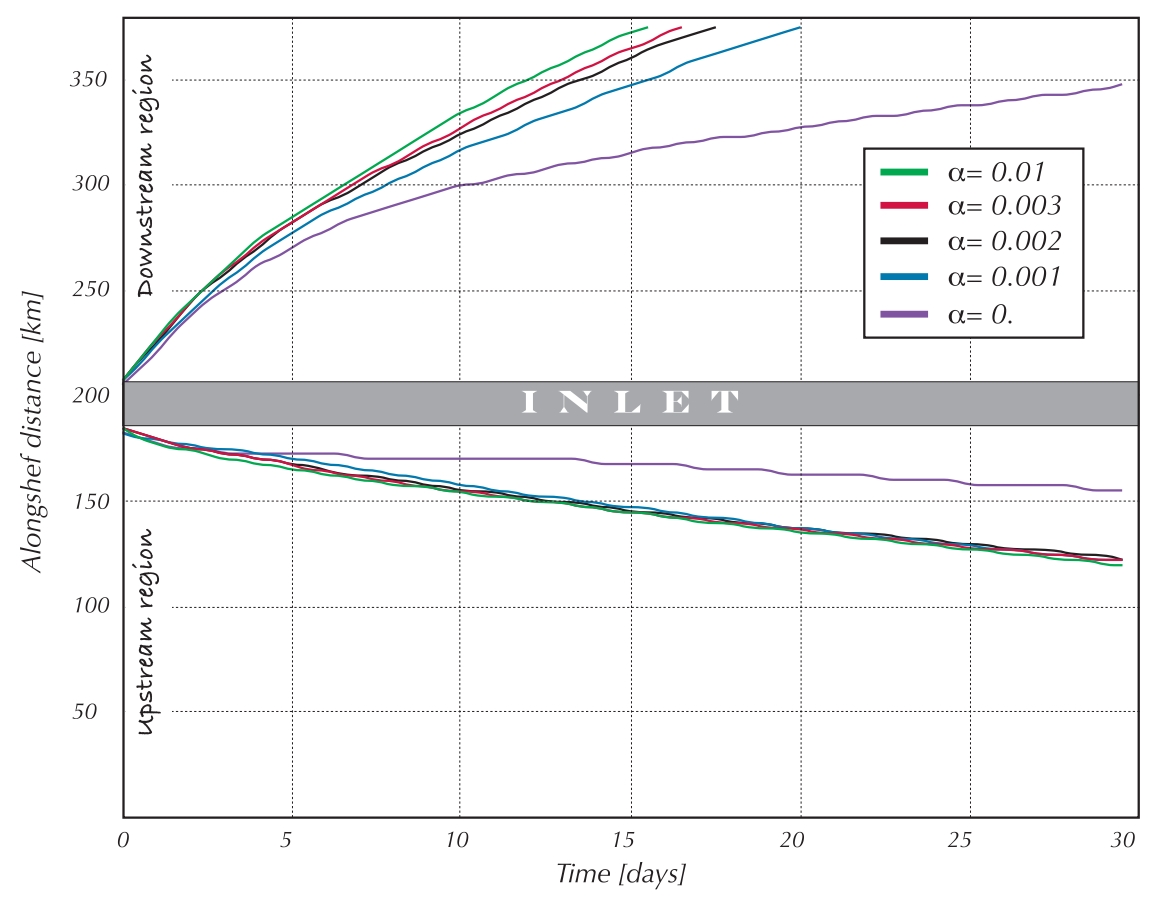

FIG. 15. Time evolution in the downstream and upstream directions of the noses of the buoyant discharge, as noted by the $\Delta \rho=0.01$ contour, for bottom topographies with different slopes $\alpha$, which corresponds to EXP3-EXP7 (Table 1).

in a flat-bottomed ocean, we did two sets of experiments with $h=30 \mathrm{~m}$ and $h=70 \mathrm{~m}$; the depth of the inlet in one set was kept at its value of $15 \mathrm{~m}$, whereas the depth of the inlet in the other set matches the depth of the bottom (EXP6 and EXP7; Table 1). The first set of experiments produced bottom-trapped plumes, whereas the second set produced surface-trapped plumes. Both sets produce bulges that spread radially around the inlet (e.g., Fig. 16), but the dynamical processes generating those bulges are qualitatively different. Pichevin and Nof (1997) and Nof and Pichevin (2001) posited that that the bulge of surfacetrapped plumes reflects the momentum imbalance of the outflow. Shaw and Csanady (1983) and Avicola and Huq (2002) argued that the bulge of bottom-trapped plumes reflects the lack the vorticity constrain on the cross-shelf flow. The fundamental difference between these paradigms is the relative importance that they ascribe to the feedback between the density and the velocity fields. The Nof and Pichevin arguments hinge on the assumption that this feedback can be neglected and therefore the only effect of the density on the velocity field is through the "reduced gravity." Such an assumption, however, cannot be applied to bottom-trapped plumes where the feedback between density and velocity plays an important role in the momentum balance of the system (e.g., Chapman and Lentz 1994). In our experiments, for example, the upstream spreading of the plume is essentially explained as a positive feedback between density advection and upstream velocities.

To investigate the sensitivity of the plume to the magnitude of the density anomaly, we did two additional simulations using discharges with $\Delta \rho=0$ (barotropic case; EXP8) and $\Delta \rho=1$ (a dense plume; EXP9; Table 1). The aim of these experiments was to show that upstream propagation is associated only with buoyant anomalies: that is, those experiments for which $\Delta \rho<0$. The results of the barotropic experiment (EXP8) are only included for the purpose of completeness, because previous studies have already shown that, in this particular case, there is no upstream excursion of the inflow (e.g., Yankovsky 2000). The steady state of the barotropic experiment is rapidly achieved through the propagation of coastally trapped waves, which sets up a cross-shelf pressure gradient and a downstream current. As predicted by the arrested topographic wave theory (Csanady 1978), bottom friction produces a widening of the $\mathrm{SSH}$ anomaly in the downstream direction (Fig. 17). The experiment with a dense discharge (EXP9) produced a bottomtrapped plume that propagated downslope and downstream (Fig. 17). There was no upstream spreading in this experiment, because a negative baroclinic pressure gradient favors downstream propagation. One of the most noticeable differences between this plume and previous one is the (gravity driven) downslope deviation of the 


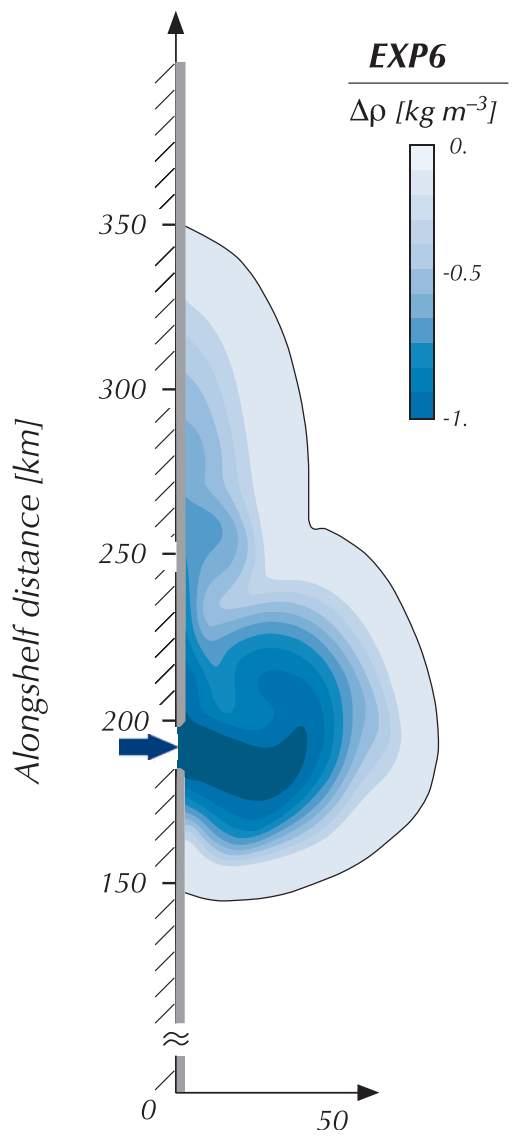

FIG. 16. Snapshots of surface density $\left(\mathrm{kg} \mathrm{m}^{-3}\right)$ at day 30 for EXP6 (flat bottom; $h=30 \mathrm{~m}$ ).

bottom density anomaly. This behavior has been observed in realistic simulations of bottom-trapped plumes in the Baltic Sea (Burchard et al. 2009), tank experiments (Cenedese et al. 2004), and analytical models (Shaw and Csanady 1983).

\section{Discussion and summary}

Sensitivity experiments indicate that upstream spreading is a robust characteristic of bottom-trapped plumes. The spreading rate and density structure of the plume are affected by bottom friction, the slope of the bottom topography, and the magnitude of the buoyant discharge. Bottom friction, particularly its development of a BBL, plays two important roles: it slows down the progression of the plume and changes its density structure. Thus, experiments including bottom friction show a slower spreading with a more homogeneous downstream region and a more stratified upstream region. Curiously, our experiments indicate that, although downstream spreading is sensitive to the slope of the bottom topography, the upstream spreading is not. We have not determined why this should be the case but speculate that it may be related to the fact that the slow rate of upstream propagation makes it difficult to observe the rates of change.

Yankovsky (2000) and Garvine (2001) identified particular model configurations (discharge conditions, angle of incidence, depth of the wall, etc.) as the cause for the upstream spreading and argued that changes in the model setup reduced such phenomenon. None of the proposed changes, however, prevented the upstream excursions of bottom-trapped plumes, but they only reduced the spreading rate. In his study of the dynamics of surfacetrapped plumes, Yankovsky (2000) proposed a new boundary condition for the discharge that allows the baroclinic adjustment of the flow near the mouth and leads to no significant upstream spreading. He correctly noted that the elimination of the upstream flow followed the conversion of what was basically a bottom-trapped plume into a surface-trapped plume, which is a different flow regime. Our experiments indicate that, to the extent that a particular model configuration generates a bottomtrapped plume, upstream spreading should be expected, because the model generates the baroclinic pressure gradient that causes the motion. Changes in the model setup that do not alter the type of plume will have no effect on upstream spreading. This is particularly true for the discharge condition, which, unless it alters the flow regime, should not affect the upstream spreading. To demonstrate this point, we did two ancillary experiments in which the inlet condition was replaced with a storage basin mimicking an estuary (EXP10 and EXP11). The magnitude of the density anomaly and the discharge was kept as in our benchmark experiment, but now the flow at the mouth of the estuary is free to adapt to the conditions in the open ocean. In spite of the substantial change of the inlet conditions, the plume, which still remains bottom trapped, moves upstream as in previous cases (Fig. 18). Interestingly, the orientation of the estuary affects the rate of downstream spreading (note that the plume of EXP10 moves at a slower rate than that of EXP11) but not the rate of upstream spreading, which appears to be insensitive to the angle of discharge. These results are in agreement with those of Garvine (2001), who noted that model changes only reduce the rate of upstream propagation but do not prevent it. The rate of upstream spreading is sensitive to the particulars of the model configuration (e.g., bottom slope, vertical mixing parameterization, etc.), but upstream spreading is a robust characteristic of bottom-trapped plumes.

In studying the dynamical mechanisms that control the offshore spreading of a buoyant plume, Chapman and Lentz (1994) posed the interesting question, "Can 


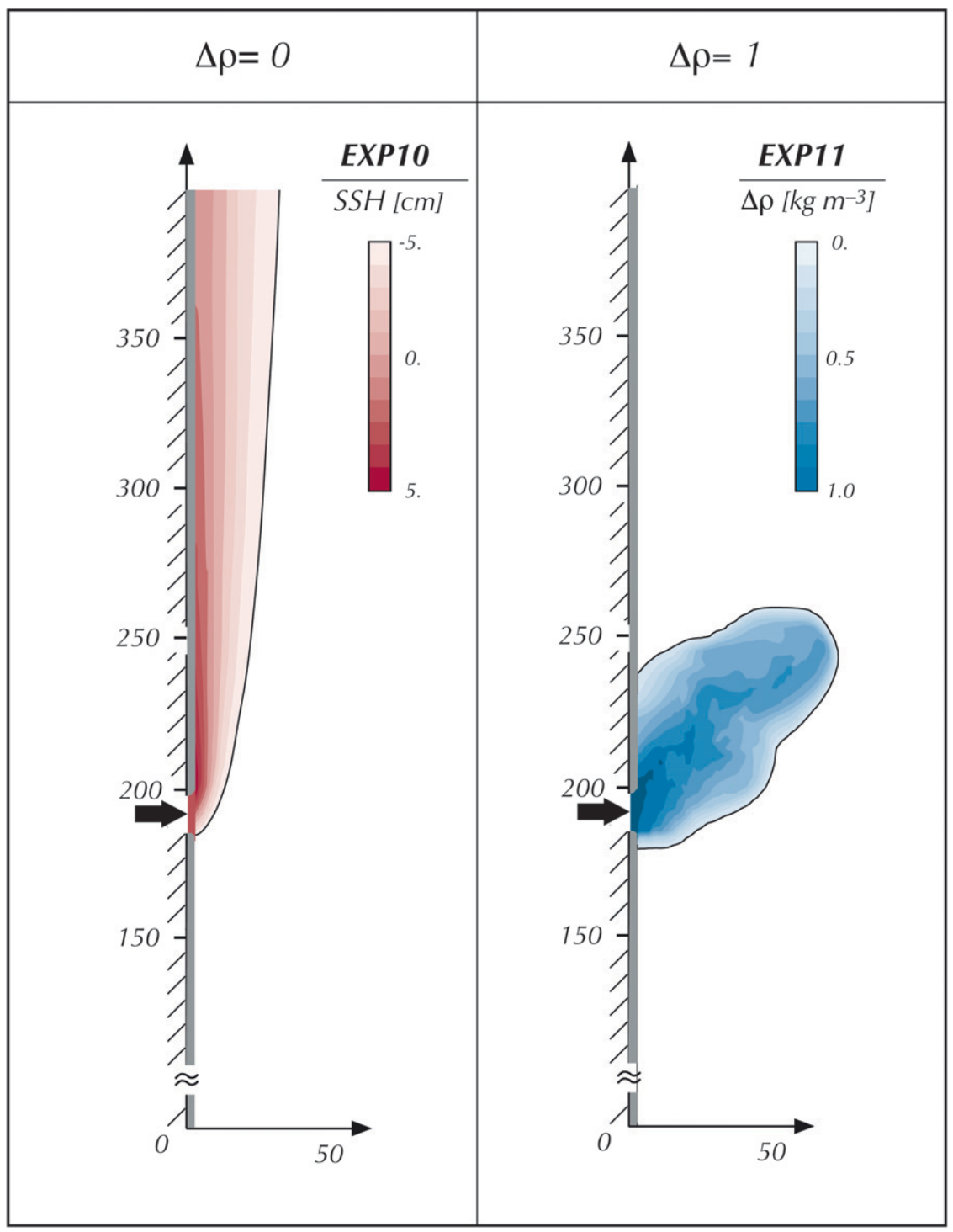

FIG. 17. Snapshots of (left) SSH at day 10 in $\operatorname{EXP8}(\Delta \rho=0)$ and (right) bottom density in EXP9 $(\Delta \rho=1)$. As predicted by theory, both plumes propagate only in the downstream direction. See Table 1 for a description of the experiments. Units are centimeters for SSH and kilograms per meter cubed for density.

the bottom boundary layer advect stratified fluid in any direction without altering the background stratification and flow?" and answered it negatively. In fact, they noted that BBL dynamics is not only important but perhaps the dominant factor. They further added, "Without the feedback between buoyancy advection in the bottom boundary layer and the velocity field, an alongshelf flow is inevitably carried seaward until it eventually leaks off the shelf and mixes with slope water." To arrive at this conclusion, they were (implicitly) comparing the offshore spreading of a homogeneous fluid with the offshore spreading of a stratified fluid. A different and perhaps equally interesting comparison is between stratified experiments with and without BBL dynamics. Our study indicates that in this case the differences are not that large. Away from the inlet, the offshore extension of a stratified plume without BBL is restricted to approximately a Rossby radius, which is the distance in which the barotropic pressure gradient set up by the coastally trapped waves overpowers the baroclinic pressure gradient set up by the advection of the density anomaly. The inclusion of a BBL moves the plume farther offshore, but the development of an upstream current is not a consequence of the offshore spreading of the plume but is 


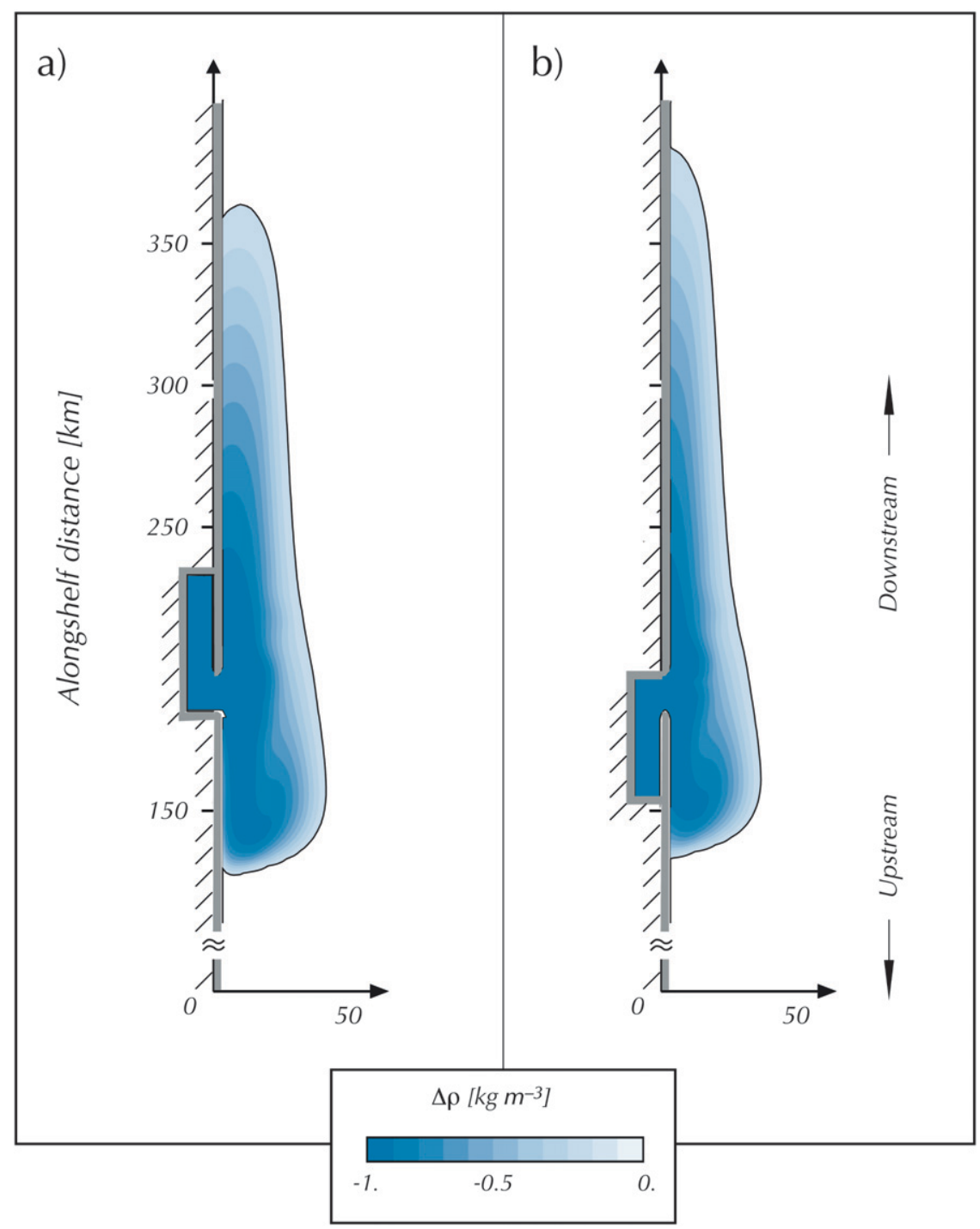

FIG. 18. Snapshots of surface density anomalies $\left(\mathrm{kg} \mathrm{m}^{-3}\right)$ in (a) EXP10 and (b) EXP11 (Table 1).

naturally associated with the existence of a baroclinic pressure gradient. Such current will develop even if there is no BBL (e.g., Fig. 13).

In summary, we have shown that [as originally posited by Chapman and Lentz (1994)] the upstream excursion of a buoyant discharge reflects the geostrophic adjustment of the density field. This phenomenon is driven by the cross-shelf baroclinic pressure gradient generated by the discharge, which tends to generate upstream motion at both sides of the buoyancy source. In the downstream side, the effect of the baroclinic pressure gradient is overpowered by the barotropic pressure gradient generated by the coastally trapped waves. However, in the upstream region, where barotropic energy cannot be leaked by coastally trapped waves, the baroclinic pressure gradient effectively drives an upstream flow. The different roles played by barotropic and baroclinic processes in the development of the plume in the downstream and upstream regions are clearly evident in our study on the spindown of a bottom-trapped plume (Matano and Palma 2010). There, we show that, if the buoyancy influx is shut off, the barotropic pressure gradient rapidly radiates away and the dynamics of the entire shelf is controlled by the baroclinic pressure gradient. Thus, a few hours after the source is turned off, the downstream velocities reverse direction and the entire density anomaly moves in the upstream direction. The dramatic changes observed in this experiment emphasize the fact that the downstream spreading of a buoyant plume is essentially a barotropic phenomenon. 
Acknowledgments. This article greatly benefited from the insightful comments and suggestions of Dr. A. Yankovsky and an anonymous reviewer. R. P. Matano acknowledges the financial support of the National Science Foundation through Grants OCE-0726994 and OCE-0928348 and of NASA through Grant NNX08AR40G. E. D. Palma acknowledges the financial support from CONICET (PIP09-112-200801), Agencia Nacional de Promoción Científica y Tecnológica (PICT081874), Universidad Nacional del Sur (24F044), and the
Inter-American Institute for Global Change Research support by the U.S. National Science Foundation Grant GEO-045325.

\section{APPENDIX}

\section{Momentum Balance}

This appendix presents the momentum balance equation:

$$
\underbrace{\frac{1}{D} \frac{\partial(D \mathbf{V})}{\partial t}}_{\text {Tendency }}+\underbrace{\mathbf{f} \times \mathbf{V}}_{\text {Coriolis }}+\underbrace{g \boldsymbol{\nabla} \eta}_{\begin{array}{c}
\text { Barotropic } \\
\text { pressure } \\
\text { gradient }
\end{array}}-\underbrace{\frac{1}{D} \boldsymbol{\nabla} \phi}_{\begin{array}{c}
\text { Baroclinic } \\
\text { pressure } \\
\text { gradient }
\end{array}}+\underbrace{\frac{1}{D} \frac{\partial}{\partial \sigma}\left(\frac{K_{M}}{D} \frac{\partial \mathbf{V}}{\partial \sigma}\right)}_{\text {Vertical diffusion }}+\underbrace{A}_{\begin{array}{c}
\text { Advection and } \\
\text { horizontal } \\
\text { diffusion }
\end{array}}=0
$$

where $\mathbf{V}$ is the horizontal velocity vector, $\mathbf{f}=f \mathbf{k}$ is the Coriolis vector, $\eta$ is the free surface elevation, $D$ is the water depth, $K_{M}$ is the coefficient of vertical viscosity, and $A$ encompasses all of the terms related to advection and horizontal diffusion. The barotropic and baroclinic pressure gradients are computed as

$$
\begin{aligned}
\nabla \eta & =\left(\frac{\partial \eta}{\partial x}, \frac{\partial \eta}{\partial y}\right)^{\mathrm{T}} \text { and } \\
\nabla \phi & =\left(\frac{\partial \phi}{\partial x}, \frac{\partial \phi}{\partial y}\right)^{\mathrm{T}} \\
& =\frac{g D^{2}}{\rho_{o}} \int_{\sigma}^{0}\left(\frac{\partial \rho}{\partial x}-\frac{\sigma}{D} \frac{\partial D}{\partial x} \frac{\partial \rho}{\partial \sigma}, \frac{\partial \rho}{\partial y}-\frac{\sigma}{D} \frac{\partial D}{\partial y} \frac{\partial \rho}{\partial \sigma}\right)^{\mathrm{T}} d \sigma .
\end{aligned}
$$

\section{REFERENCES}

Avicola, G., and P. Huq, 2002: Scaling analysis for the interaction between a buoyant coastal current and the continental shelf: Experiments and observations. J. Phys. Oceanogr., 32, 3233 3248.

Beardsley, R. C., R. Limeburner, H. Yu, and G. A. Cannon, 1985: Discharge of the Changjiang (Yangtze River) into the East China Sea. Cont. Shelf Res., 4, 57-76.

Blumberg, A. F., and G. L. Mellor, 1987: A description of a threedimensional coastal ocean circulation model. Three-Dimensional Coastal Ocean Models, N. S. Heaps, Ed., Coastal and Estuarine Sciences Series, Vol. 4, Amer. Geophys. Union, $1-16$.

Brink, K. H., 1991: Coastal-trapped waves and wind-driven currents over the continental shelf. Annu. Rev. Fluid Mech., 23, 389-412.

Burchard, H., F. Janssen, K. Bolding, and L. Umlauf, 2009: Model simulations of dense bottom currents in the western Baltic Sea. Cont. Shelf Res., 29, 205-220.

Cenedese, C., J. A. Whitehead, T. A. Ascarelli, and M. Ohiwa, 2004: A dense current flowing down a sloping bottom in a rotating fluid. J. Phys. Oceanogr., 34, 188-203.
Chao, S.-Y., and W. C. Boicourt, 1986: Onset of estuarine plume. J. Phys. Oceanogr., 16, 2137-2149.

Chapman, D. C., and S. J. Lentz, 1994: Trapping of coastal density front by the bottom boundary layer. J. Phys. Oceanogr., 24, 1464-1479.

Csanady, G. T., 1978: The arrested topographic wave. J. Phys. Oceanogr., 8, 47-62.

Fong, D. A., 1998: Dynamics of freshwater plumes: Observations and numerical modeling of the wind-forced response and alongshore freshwater transport. Ph.D. dissertation, Massachusetts Institute of Technology and Woods Hole Oceanographic Institution, $172 \mathrm{pp}$.

— , and W. R. Geyer, 2002: The alongshore transport of freshwater in a surface-trapped river plume. J. Phys. Oceanogr., 32, 957-972.

Framiñan, M., 2005: On the physics, circulation, and exchanges processes of the Rio de la Plata estuary and adjacent shelf. Ph.D. Dissertation, University of Miami, $486 \mathrm{pp}$.

Garvine, R. W., 1999: Penetration of buoyant coastal discharge onto the continental shelf: A numerical model experiment. J. Phys. Oceanogr., 29, 1892-1909.

— 2001: The impact of model configuration in studies of buoyant coastal discharge. J. Mar. Res., 59, 193-225.

Guo, X., and A. Valle-Levinson, 2007: Tidal effects on estuarine circulation and outflow plume in the Chesapeake Bay. Cont. Shelf Res., 27, 20-42.

Kourafalou, V. H., L.-Y. Oey, J. D. Wang, and T. N. Lee, 1996: The fate of river discharge on the continental shelf. 1. Modeling the river plume and inner shelf coastal current. J. Geophys. Res., 101, 3415-3434.

Kubokawa, A., 1991: On the behavior of outflows with low potential vorticity from a sea strait. Tellus, 43A, 168-176.

Matano, R. P., and E. D. Palma, 2008: On the upwelling of downwelling currents. J. Phys. Oceanogr., 38, 2482-2500.

$\longrightarrow$, and — 2010: The spindown of bottom-trapped plumes. J. Phys. Oceanogr., 40, 1651-1658.

McCreary, J. P., S. Zhang, and S. R. Shetye, 1997: Coastal circulation driven by river outflow in a variable-density $1 \frac{1}{2}$-layer model. J. Geophys. Res., 102, 15 535-15 554.

Mellor, G. L., and T. Yamada, 1982: Development of a turbulent closure model for geophysical fluid problems. Rev. Geophys. Space Phys., 20, 851-868. 
Murty, V. S. N., Y. V. B. Sarma, D. P. Rao, and C. S. Murty, 1992: Water characteristics, mixing and circulation in the Bay of Bengal during southwest monsoons. J. Mar. Res., 50, 207-228.

Narayanan, C., and R. W. Garvine, 2002: Large scale buoyancy driven circulation on the continental shelf. Dyn. Atmos. Oceans, 36, 125-152.

Nof, D., and T. Pichevin, 2001: The ballooning of outflows. J. Phys. Oceanogr., 31, 3045-3058.

Palma, E. D., and R. P. Matano, 1998: On the implementation of open boundary conditions to a general circulation model: The barotropic mode. J. Geophys. Res., 103, 1319-1341.

- , and - 2000: On the implementation of open boundary conditions for a general circulation model: The threedimensional case. J. Geophys. Res., 105 (C4), 8605-8627.

Pichevin, T., and D. Nof, 1997: The momentum imbalance paradox. Tellus, 49A, 298-319.

Piola, A. R., S. I. Romero, and U. Zajaczkovski, 2008: Space-time variability of the Plata plume inferred from ocean color. Cont. Shelf Res., 28, 1556-1567.
Shaw, P. T., and G. T. Csanady, 1983: Self-advection of density perturbations on a sloping continental shelf. J. Phys. Oceanogr., 13, 769-782.

Smolarkiewicz, P. K., and W. W. Grabowski, 1990: The multidimensional positive definite advection transport algorithm: Nonoscillatory option. J. Comput. Phys., 86, 355-375.

Weingartner, T. J., S. Danielson, Y. Sasaki, V. Pavlov, and M. Kulakov, 1999: The Siberian Coastal Current: A wind- and buoyancy-forced Arctic coastal current. J. Geophys. Res., 104, 29 697-29 713.

Woods, A. W., and R. C. Beardsley, 1988: On the barotropic discharge of a homogeneous fluid onto a continental shelf. Cont. Shelf Res., 8, 307-327.

Yankovsky, A. E., 2000: The cyclonic turning and propagation of buoyant coastal discharge along the shelf. J. Mar. Res., 58, 585-607.

, and D. C. Chapman, 1997: A simple theory for the fate of buoyant coastal discharges. J. Phys. Oceanogr., 27, 13861401. 